\title{
Pricing Behaviour and the Role of Trade Openness in the Transmission of Monetary Shocks
}

\author{
Laura Povoledo \\ Bristol Centre for Economics and Finance, \\ Bristol Business School, UK
}




\title{
Pricing Behaviour and the Role of Trade Openness in the Transmission of Monetary Shocks
}

\author{
Laura Povoledo* \\ University of the West of England ${ }^{\dagger}$
}

January 2018

\begin{abstract}
The empirical evidence on the role of trade openness in the monetary transmission is not conclusive: some studies find that it increases the sensitivity of output to monetary shocks, others find that it does not. Using a New Keynesian open economy model, I show that the role of trade openness in the transmission of monetary shocks can be reversed completely by the degree of exchange-rate pass-through into import prices. If the pass-through is complete, traded output increases more than nontraded output after a positive monetary shock, if the pass-through is zero, traded output increases less. Moreover, ignoring sectoral heterogeneity in price rigidity leads to an incorrect assessment of the role of trade openness in the transmission of monetary shocks.
\end{abstract}

JEL Classification E32; F41.

Keywords: Monetary transmission; Traded and nontraded output; Exchange rate pass-through; Openness; Sectoral disaggregation.

\footnotetext{
${ }^{*}$ I am grateful to Iris Biefang-Frisancho Mariscal, Yannis Dafermos, Georgios Georgiadis and Michail Veliziotis for their useful comments. I also thank seminar participants at the Bank of England and the 2017 MMF annual conference for their comments and discussion. Any errors or shortcomings are my sole responsibility.

${ }^{\dagger}$ Coldharbour Lane, Bristol BS16 1QY (UK). Tel: 004411732 83723. Email: Laura.Povoledo@uwe.ac.uk.
} 


\section{Introduction}

The importance of external demand in the transmission of monetary shocks to aggregate output is recognised in the central bank literature. For example, according to the Bank of England's transmission mechanism of monetary policy (1999), the exchange rate and net external demand are important links in the chain of transmission connecting monetary policy to the aggregate economy. And according to the European Central Bank (ECB 2011), the degree of openness to international trade affects the transmission of monetary policy changes through the exchange rate.

Given the recognised role of external demand in the transmission mechanism, does greater exposure to international trade increase the sensitivity of output to monetary shocks? The empirical literature shows that the answer to this question is not unique. Some studies suggest that trade openness increases the response of output to monetary shocks, while other studies suggest that trade openness does not matter. In this paper, I investigate two potential explanations for such conflicting findings, namely the degree of exchange rate pass-through and the extent to which the degree of price rigidity differs between the traded and the nontraded sectors.

I present a New Keynesian open economy Dynamic Stochastic General Equilibrium (DSGE) model with traded and nontraded sectors, and I show that the role of trade openness in the monetary transmission can be explained with the aid of a simple figure. In particular, I show that the short-run equilibrium can be characterized by two conditions that relate the tradednontraded output ratio to the traded-nontraded price ratio (top of Figure 1). First, there is a downward-sloping "demand" relationship, obtained by manipulating the Home and Foreign demands for traded and nontraded goods and the resource constraints. Secondly, there is an upward-sloping "supply" relationship, which can be obtained from the first-order condition of the firms' maximization problem. If trade openness increases the sensitivity of output to monetary shocks, then the response of traded output must be higher than the response of nontraded output, resulting in an increase in the traded to nontraded output ratio.

Consider for example a positive monetary shock. Under a standard parametrization, a positive monetary shock causes a nominal depreciation and an increase in domestic bond holdings. As external demand increases, the demand schedule shifts to the right (Figure 3). ${ }^{1}$ If the pass-

\footnotetext{
${ }^{1}$ In the model, the increase in external demand is caused by two effects. First, an increase in bond holdings relative to the steady state implies that the Foreign country increases consumption through debt, thus the demand for Home exports of traded goods increases. Secondly, if the nominal exchange rate depreciation is passed into export prices, Home traded goods become comparatively less expensive and their demand increases
} 
through is one, then there is no change in the supply schedule, so traded output increases more (is more affected) than nontraded output after a monetary shock (equilibrium B). ${ }^{2}$ However, if the pass through is equal to zero, then the relative supply shifts up, since Home traded sector firms receive more Home currency for each unit of output sold abroad, thus nontraded output increases more than traded output after a monetary shock (equilibrium $\mathrm{C}$ ). Therefore, the role of trade openness in the transmission of monetary shocks can be completely reversed by the pass-through elasticity.

The empirical research shows that there are different ways of investigating the role of trade openness in the monetary transmission. ${ }^{3}$ For example, some papers analyse manufacturing or industry-level data to study whether the heterogenous effects of identified monetary shocks can be explained by various industry characteristics, among which is a measure of export openness. This approach has been followed by Hayo and Uhlenbrock (2000), who find that trade openness increases the sensitivity to monetary shocks, and by Dedola and Lippi (2005) and Peersman and Smets (2005), who instead find that trade openness does not matter. Other approaches consider more sectors (in addition to manufacturing or industry), or study the differential regional effects of monetary shocks. Overall, the empirical literature does not provide clear evidence either in favour or against the hypothesis that trade openness increases the sensitivity of output to monetary shocks.

Using artificial time series generated by the model, I provide an estimate of the impact of monetary shocks on traded and nontraded output, and I show that such estimate crucially depends on the degree of exchange rate pass-through and on the extent of sectoral heterogeneity in price rigidity. If the two sectors have the same degree of price rigidity, then it is possible to find an intermediate value of the pass-through elasticity such that the responses of traded and nontraded output after a monetary shock are the same, thus rationalizing why trade openness is not correlated with a stronger output response in some studies. If prices are more rigid in the nontraded sector and the pass-through elasticity is below one, then nontraded output responds more to a monetary shock than traded output. Overall, these results evidence the importance of controlling for both the pass-through elasticity and the degree of price rigidity in an empirical

${ }^{2}$ The variables on the horizontal and vertical axis are, respectively, the log of the traded-nontraded output ratio $\widehat{Y}_{T H, t}-\widehat{Y}_{N, t}$ and the log of the traded-nontraded price ratio. If $\widehat{Y}_{T H, t}-\widehat{Y}_{N, t}$ increases (decreases) after a monetary shock, then traded output responds more (less) than nontraded output.

${ }^{3} \mathrm{~A}$ summary of the related literature on the heterogenous effects of monetary shocks can be found in Section 2 .
} 
investigations of the sectoral effects of monetary policy.

This paper is related to the literature that examines the implications of traded and nontraded goods on the business cycle properties and the transmission of monetary shocks in New Keynesian open economy models. Assuming full pass-through, Hau (2000) and Rabanal and Tuesta (2012) find that nontraded goods play an important role in explaining exchange rate fluctuations. Duarte and Obstfeld (2008) and Lombardo and Ravenna (2014) instead assume no pass-through from exchange rate changes to import prices, and they find that nontraded goods affect the optimal volatility of the exchange rate. Other studies with traded and nontraded sectors assume that the degree of pass-through is between zero and one. For example, Dotsey and Duarte (2008) generate incomplete pass-through by introducing nontraded distribution services. They find that nontraded goods improve the performance of the model relative to the data, in particular, nontraded goods increase the volatility of the real and nominal exchange rates. This paper departs from this literature since I focus on the sectoral output responses, and I analyse how the role of trade openness in the transmission of monetary shocks is affected by the modelling assumptions.

The remainder of the paper is as follows. Section 2 discusses the empirical evidence on the role of trade openness in the transmission of monetary shocks. The model is presented in Section 3, and the demand and supply approach to the analysis of the short-run effects of monetary shocks is explained in Section 4 . The responses to monetary shocks and the estimated output effects from the regressions on artificial data are discussed in Section 5. Finally, Section 6 concludes.

\section{Empirical Evidence}

The importance of external demand in the transmission mechanism of monetary shocks is recognised in the central bank literature. For example, according to the Bank of England's transmission mechanism of monetary policy (1999), an unexpected increase in the policy rate normally leads to a nominal appreciation, which results in a fall in the competitiveness of domestic producers of exports and of import-competing goods, consequently aggregate demand falls and domestic inflationary pressure is reduced. An unexpected decrease in the policy rate has the opposite effect. Analogously, the European Central Bank (ECB 2011) suggests that exchange rate changes affect the international competitiveness of domestically produced goods, thereby 
affecting demand-side inflationary pressures. ${ }^{4}$

The ability of monetary policy to affect the international competitiveness of domestic goods provides the motivation for a closely related research question. Are the output effects of monetary policy shocks more pronounced in the traded goods sectors, that is, in the sectors that export a relatively higher share of their output and are exposed to the competition of Foreignproduced goods? This question is addressed, directly or indirectly, by several contributions within the literature on the sectoral or industry effects of monetary policy shocks.

Some authors analyse manufacturing or industry-level data to examine the relationship between the impact of monetary policy shocks and various industry characteristics, among which is a measure of export openness. ${ }^{5}$ Hayo and Uhlenbrock (2000) estimate the reaction of the industries in the German manufacturing and mining sectors to a monetary policy shock. They find that export-oriented industries react more negatively after a contractionary monetary shock. However, other authors report different findings. Dedola and Lippi (2005) study the effects of monetary policy shocks on the industrial activity of 21 manufacturing sectors in five OECD countries. They find that the industry export ratio has no significant effect on the impact of monetary shocks. Peersman and Smets (2005) analyse the effects of a monetary policy change on the output of eleven manufacturing industries of seven euro area countries over the period 1980-98. They measure openness as the ratio of exports plus imports over value added in each industry, and they find that it is not important in explaining the heterogenous effects of monetary policy. ${ }^{6}$

Other authors also study the heterogeneous effects of monetary policy but consider other sectors as well as manufacturing or industry. From these studies we can gauge the importance of trade openness by comparing the responses of the traded sectors with the responses of nontraded sectors to monetary shocks. It is common in the literature to classify a sector as traded if its openness ratio (the sum of exports plus imports divided by the sector's value added) exceeds a certain threshold. ${ }^{7}$ According to this methodology, manufacturing, mining and agriculture are usually classified as traded, while construction, government, finance and services are classi-

\footnotetext{
${ }^{4}$ Notice that the exchange rate also affects inflation directly, via the domestic price of imported intermediate and final goods. Such direct effect is conceptually distinct from the indirect effect of the exchange rate on inflation via net external demand (the difference between exports and imports).

${ }^{5}$ Provided exports are a substitute for Foreign traded goods, export openness is a valid proxy for the degree of tradability of a given sector's output.

${ }^{6}$ All the empirical studies cited in this Section use a VAR approach in the identification and estimation of monetary shocks.

${ }^{7}$ In Betts and Kehoe (2001) such threshold is $10 \%$.
} 
fied as nontraded. Since traded goods are the goods that are exported and/or are substitutable with imports, a stronger response of the traded sectors (relatively to the nontraded sectors) to a monetary shock is evidence of the importance of trade openness in the transmission mechanism. A number of studies report findings that support this hypothesis. Farès and Srour (2001) find that, following a monetary contraction, manufacturing reacts twice as strongly than construction, and the response of the service sector is half as strong as manufacturing. They also find that a monetary contraction affects exports relatively quickly. Doyle, Erceg and Levin (2005) construct measures of traded and nontraded output using sectoral data for Australia, Canada, Sweden and the United Kingdom. They find that contractionary monetary policy shock causes output to decline by roughly twice as much in the traded sector than in the nontraded sector. Llaudes (2007) identifies manufacturing as the traded sector and services as the nontraded sector. Using two different identification schemes, he finds that traded output is more responsive to monetary policy shocks than nontraded output in all countries in the sample.

However, some of the studies which consider a broader range of sectors do not lend support to a significant role of trade openness in the transmission of monetary shocks. These studies find that the sectors that are most responsive to monetary shocks are some nontraded sectors whose output demand is interest-sensitive (typically, construction and finance). Such findings do not necessarily imply that trade openness plays no role in the monetary transmission, but they seem to suggest that it matters less than the interest-sensitivity of demand, especially if the responses of construction or finance to a monetary shock are well above the response of manufacturing. ${ }^{8}$ Using UK data, Ganley and Salmon (1997) find that manufacturing is more sensitive to monetary shocks than government and financial services, however, the construction and distribution sectors have the largest absolute responses. Using highly disaggregated data for the US economy, Arnold (2013) finds that finance and construction are even more sensitive to monetary shocks than manufacturing.

Monetary shocks have different effects not only across sectors, but also across regions or geographical areas. The literature on the regional effects of monetary shocks may also be useful for understanding the role of trade openness in the transmission of monetary shocks, because some authors include variables that are positively correlated with openness in their set of explanatory factors. For example, Carlino and DeFina (1998) study US states and regions,

\footnotetext{
${ }^{8}$ Notice however that the demand for manufacturing goods (especially durables) is also considered to be interest-sensitive.
} 
and find a positive correlation between the responses to monetary policy shocks and the share of manufacturing in the state's gross product. This finding is confirmed by Mihov (2001) and Owyang and Wall (2004). Georgiadis (2015) focuses on euro area economies, and finds that the output response after a common euro area contractionary monetary shock is more negative if the share of output accounted for by manufacturing (both durable and total) is comparatively large, but less negative if the share of output accounted for by services is comparatively large. Moreover, he finds that the relationship between the sensitivity to monetary shocks and the share of output accounted for by construction is not significant. On the other hand, Arnold and Vrugt (2004) do not find a statistically significant relationship between the sensitivity to monetary shocks and the export share of German regions. However, they also find that a higher share of public and personal services in a region's GDP reduces the sensitivity to monetary policy shocks, and a higher share of manufacturing in GDP increases the regional sensitivity to monetary policy shocks.

In summary, the empirical evidence on the role of trade openness is not yet conclusive. Some studies are consistent with the proposition that trade openness increases the sensitivity to monetary shocks, while other studies seem to suggest that trade openness does not matter as much as other characteristics, such as the sensitivity of demand to interest rate changes. This paper aims to shed light on this issue by analysing two factors that crucially affect the magnitude of the response of traded output relative to nontraded output: the degree of exchange rate pass-through and the degree of price rigidity in each sector.

\section{The model}

The world economy consists of two countries of equal size, named Home and Foreign. Each country has two sectors, one for the production of traded and one for nontraded goods. In each country and in each sector a continuum of monopolistically competitive firms exist, each of them producing a single differentiated product. The firms and the goods they produce are indexed by $f_{T H} \in[0,1]$ for the Home traded sector and $f_{N} \in[0,1]$ for the Home nontraded sector. In the Foreign country, they are indexed by $f_{T F}^{*} \in[0,1]$ and $f_{N}^{*} \in[0,1]$. Each country is populated by a continuum of unit size of individuals. All foreign variables, sets and indexes are indicated by stars. 


\subsection{Individual preferences and budget constraints}

Each individual is endowed with one unit of time, a fraction of which can be supplied as labour either to the traded goods sector or to the nontraded goods sector. Any individual who works incurs a fixed participation cost, as in Burnside, Eichenbaum and Rebelo (1993). There is no possibility of migration across countries, but individuals can move costlessly from one sector to the other within each country. However, labour services cannot be contemporaneously supplied to both the traded and nontraded goods sector.

Following Rogerson (1988), I add to the individual maximization problem the probabilities of working in each sector. That is, I write the utility of a Home individual as follows:

$$
U_{0}=E_{0} \sum_{t=0}^{\infty} \beta^{t}\left[\begin{array}{c}
\frac{C_{t}^{1-\sigma}-1}{1-\sigma}+\frac{\chi}{1-\varepsilon}\left(\frac{M_{t}}{P_{t}}\right)^{1-\varepsilon}+n_{T H, t} \cdot \kappa\left(\Gamma-\psi-\mathbf{h}_{T H, t}\right) \\
+n_{N, t} \cdot \kappa\left(\Gamma-\psi-\mathbf{h}_{N, t}\right) \\
+\left(1-n_{T H, t}-n_{N, t}\right) \cdot \kappa(\tau)
\end{array}\right]
$$

where $C$ is the aggregate consumption index, $\frac{M}{P}$ are real money balances, $n_{T H}, n_{N}$ are the probabilities of working in the traded and nontraded sector respectively, $\psi$ is a fixed cost of participation, the same for all individuals, ${ }^{9}$ and $\mathbf{h}_{T H}=\int_{0}^{1} h_{T H}\left(f_{T H}\right) d f_{T H}$ and $\mathbf{h}_{N}=\int_{0}^{1} h_{N}\left(f_{N}\right) d f_{N}$ are the total hours that the individual supplies to the sectors $T H$ and $N$ respectively.

Foreign preferences are similarly written, with the same parameters $\sigma, \chi, \varepsilon, \Gamma, \tau$ and $\psi$ and functional form $\kappa$.

Home and Foreign individuals hold a one-period non-contingent real bond, denominated in units of the Home traded goods consumption index, sold at the price $P_{T}$. Individuals must pay a small cost in order to undertake a position in the international asset market. ${ }^{10}$ This cost is assumed to be a payment in exchange for the intermediation services offered by financial firms. Home and Foreign individuals pay this cost only to firms located in their own country.

The period- $t$ budget constraint of the representative individual in the Home country is as follows:

\footnotetext{
${ }^{9}$ Total time available is different for the employed $(\Gamma)$ and the unemployed $(\tau)$. By assuming that $\tau$ is sufficiently small, it is possible to ensure that the unemployed do not enjoy greater utility ex-post than the employed.

${ }^{10}$ This assumption ensures stationarity of the model and a well-defined steady state, as demonstrated by Schmitt-Grohe and Uribe (2003).
} 


$$
\begin{gathered}
B_{t} P_{T, t}+\frac{\nu}{C_{0}} B_{t}^{2} P_{T, t}+M_{t} \leq\left(1+r_{t-1}\right) B_{t-1} P_{T, t}+M_{t-1} \\
\quad+T R_{t}-P_{t} C_{t}+n_{T H, t} W_{T H, t} \mathbf{h}_{T H, t}+n_{N, t} W_{N, t} \mathbf{h}_{N, t} \\
\quad+\int_{0}^{1} \Pi_{T H, t}\left(f_{T H}\right) d f_{T H}+\int_{0}^{1} \Pi_{N, t}\left(f_{N}\right) d f_{N}+R_{t},
\end{gathered}
$$

where $B$ is the internationally traded bond, $\frac{\nu}{C_{0}} B$ is the cost of holding one unit of the bond, ${ }^{11}$ which depends on the positive parameter $\nu, M$ are nominal money balances, $r$ is the real interest rate, $T R$ are government transfers, $W_{T H}$ and $W_{N}$ are the wages paid in the traded and nontraded sector respectively, ${ }^{12} \Pi_{T H}\left(f_{T H}\right)$ and $\Pi_{N}\left(f_{N}\right)$ are the profits that the individual receives from firms $f_{T H}$ (traded sector) and $f_{N}$ (nontraded sector), and $R$ represents the rents generated by the financial intermediaries. ${ }^{13}$ The budget constraint of Foreign individuals is analogous. The internationally traded bond $B$ is in zero net supply worldwide.

\subsubsection{Consumption indexes}

The preferences over traded and nontraded goods in the Home country are specified as follows:

$$
C_{t}=\left[(1-\gamma)^{\frac{1}{\phi}}\left(C_{T, t}\right)^{\frac{\phi-1}{\phi}}+\gamma^{\frac{1}{\phi}}\left(C_{N, t}\right)^{\frac{\phi-1}{\phi}}\right]^{\frac{\phi}{\phi-1}}
$$

where $(1-\gamma)$ and $\gamma$ are preference weights, and $\phi$ is the substitution elasticity. Preferences in the Foreign country are described by an equivalent aggregator, with the same parameters $\gamma$ and $\phi$.

The aggregators for traded goods consumption in the Home and Foreign countries at date $t$ are, respectively:

$$
\begin{gathered}
C_{T, t}=\left[(1-\delta)^{\frac{1}{\theta}}\left(C_{T H, t}\right)^{\frac{\theta-1}{\theta}}+\delta^{\frac{1}{\theta}}\left(C_{T F, t}\right)^{\frac{\theta-1}{\theta}}\right]^{\frac{\theta}{\theta-1}}, \\
C_{T, t}^{*}=\left[\delta^{\frac{1}{\theta}}\left(C_{T H, t}^{*}\right)^{\frac{\theta-1}{\theta}}+(1-\delta)^{\frac{1}{\theta}}\left(C_{T F, t}^{*}\right)^{\frac{\theta-1}{\theta}}\right]^{\frac{\theta}{\theta-1}} .
\end{gathered}
$$

\footnotetext{
${ }^{11} C_{0}$ denotes the steady-state value of Home consumption.

${ }^{12}$ The budget constraint states that the individual receives the expected income. Because of the law of large numbers, the probabilities chosen at the individual level and the fraction of individuals at the aggregate level that work in a given sector coincide.

${ }^{13}$ Individuals are allocated to the sectors randomly, but they can perfectly share the income risk resulting from the lottery. All individuals then receive the average wage, given their chosen $n_{T H}$ and $n_{N}$, as demonstrated by Rogerson (1988). Hence probabilities appear in the budget constraint (2).
} 
The preferences for the individual goods or varieties are also represented by CES aggregators, for example, in the Home country the preferences for the domestic traded varieties are given by:

$$
C_{T H, t}=\left[\int_{0}^{1} c_{T H, t}\left(f_{T H}\right)^{\frac{\eta-1}{\eta}} d f_{T H}\right]^{\frac{\eta}{\eta-1}}
$$

\subsubsection{Government budget constraint and money supply}

The Home and Foreign governments purchase only nontraded goods ${ }^{14}$ produced in their own country. As in Chari, Kehoe and McGrattan's (2002) model, money growth rates follow AR(1) processes, whose unconditional mean is zero. Therefore, the target of monetary policy is a money growth rate of zero. The budget constraint of the Home government at date $t$ is given by:

$$
M_{t}-M_{t-1}=P_{N, t} G_{t}+T R_{t}
$$

where $G$ is a public expenditure aggregator or production function:

$$
G_{t}=\left[\int_{0}^{1} g_{t}\left(f_{N}\right)^{\frac{\eta-1}{\eta}} d f_{N}\right]^{\frac{\eta}{\eta-1}}
$$

The Foreign government budget constraint and the public expenditure aggregator are entirely analogous. Government expenditures in both countries follow AR(1) processes with an unconditional mean of zero.

\subsection{Firms}

I introduce nominal rigidities à la Calvo (1983), by assuming that firms change their prices infrequently, and each firm has a fixed probability of changing its prices at date $t$. An important issue in two-country, two-currency models is the choice of currency of invoicing. For example, Obstfeld and Rogoff (1995) assume that the law of one price holds and that prices are sticky in the currency of the producer, while Betts and Devereux $(1996,2000)$ assume that prices are sticky in the currency of the destination market. I assume that traded goods firms in both countries set two different prices, one for the Home market and one for the Foreign market,

\footnotetext{
${ }^{14}$ According to the Bureau of Economic Analysis' "Guide to the National Income and Product Accounts of the United States", government expenditure essentially consists of services provided to the public free of charge.
} 
and that the price for the Foreign market can adjust to changes in the nominal exchange rate, as in Corsetti and Pesenti (2005). Specifically, I assume that the export prices ${ }^{15}$ of Home and Foreign traded varieties $f_{T H}$ and $f_{T F}^{*}$ are given, respectively, by:

$$
p_{T H, t}^{*}\left(f_{T H}\right)=\frac{\widetilde{p}_{T H, t}\left(f_{T H}\right)}{e_{t}^{\zeta}}, \quad p_{T F, t}\left(f_{T F}^{*}\right)=e_{t}^{\zeta} \tilde{p}_{T F, t}^{*}\left(f_{T F}^{*}\right)
$$

where $e_{t}$ is the nominal exchange rate (the price of the Home currency in terms of the Foreign currency) at date $t, \widetilde{p}_{T H}\left(f_{T H}\right)$ and $\widetilde{p}_{T F}^{*}\left(f_{T F}^{*}\right)$ are predetermined components that are chosen in period $t$, and $\zeta$ is the elasticity of exchange rate pass-through, constant by assumption. The pass-through elasticity can be calibrated at any level between zero and one. ${ }^{16}$

The Home traded sector firm $f_{T H}$ chooses the price $p_{T H, t}\left(f_{T H}\right)$ of domestic sales, and the predetermined component $\widetilde{p}_{T H, t}\left(f_{T H}\right)$ of the export price, by solving the following problem: ${ }^{17}$

$$
\max \quad E_{t} \sum_{j=0}^{\infty}(\varphi \beta)^{j} Q_{t, t+j}\left[\begin{array}{c}
\frac{p_{T H, t}\left(f_{T H}\right)}{P_{t+j}} \cdot y_{T H, t+j \mid t}^{H}\left(f_{T H}\right) \\
+e_{t+j} \frac{p_{T H, t+j}^{*}\left(f_{T H}\right)}{P_{t+j}} y_{T H, t+j \mid t}^{F}\left(f_{T H}\right) \\
-\frac{W_{T H, t+j}}{P_{t+j}} \cdot \widetilde{h}_{T H, t+j \mid t}\left(f_{T H}\right)
\end{array}\right],
$$

subject to:

$$
\begin{aligned}
y_{T H, t+j \mid t}^{H}\left(f_{T H}\right) & =\left(\frac{p_{T H, t}\left(f_{T H}\right)}{P_{T H, t+j}}\right)^{-\eta} C_{T H, t+j}, \\
y_{T H, t+j \mid t}^{F}\left(f_{T H}\right) & =\left(\frac{p_{T H, t+j}^{*}\left(f_{T H}\right)}{P_{T H, t+j}^{*}}\right)^{-\eta} C_{T H, t+j}^{*}, \\
p_{T H, t+j}^{*}\left(f_{T H}\right) & =\widetilde{p}_{T H, t}\left(f_{T H}\right) e_{t+j}^{-\zeta},
\end{aligned}
$$

where $Q_{t, t+j}=\frac{u^{\prime}\left(C_{t+j}\right)}{u^{\prime}\left(C_{t}\right)}$, and $(\varphi)^{j}$ is the probability that $p_{T H, t}\left(f_{T H}\right)$ and $\widetilde{p}_{T H, t}\left(f_{T H}\right)$ still apply at the future date $t+j$. The variables $y_{T H, t+j \mid t}^{H}\left(f_{T H}\right), y_{T H, t+j \mid t}^{F}\left(f_{T H}\right)$ and $\widetilde{h}_{T H, t+j \mid t}\left(f_{T H}\right)$ respectively denote output sold at Home and abroad and the total labour input used by the firm, if the prices decided at $t$ still apply at date $t+j$.

\footnotetext{
${ }^{15}$ Prices of individual varieties are denoted with lower cases, price indexes (the prices of the consumption aggregators) are denoted with upper cases. Price indexes are defined in the standard way, as the minimal expenditures needed to buy one unit of the corresponding consumption aggregators.

${ }^{16}$ If $\zeta^{*}$ and $\zeta$ are equal to one prices are essentially sticky in the producer's currency and the exchange rate pass-through is complete. If $\zeta^{*}$ and $\zeta$ are equal to zero prices are sticky in the local currency and the exchange rate pass-through is zero.

${ }^{17}$ In this model firms take into account the demand for their product when maximizing profits, but they take the individuals' allocative choices and supply of hours as given. The assumptions on the functional forms and the requirement that $\alpha \leq 1$ ensure that profits are a concave function of prices.
} 
The production function of firm $f_{T H}$ is:

$$
y_{T H, t}^{H}\left(f_{T H}\right)+y_{T H, t}^{F}\left(f_{T H}\right)=z_{T H, t} \cdot \widetilde{h}_{T H, t}\left(f_{T H}\right)^{\alpha}
$$

where $\alpha$ is a parameter that allows for decreasing returns to labour, and $z_{T H}$ represents technology, which affects the productivity of labour. Wages are flexible. Firm $f_{T H}$ uses an aggregate of all labour inputs which is given by: ${ }^{18}$

$$
\widetilde{h}_{T H, t}\left(f_{T H}\right)=n_{T H, t} h_{T H, t}\left(f_{T H}\right) .
$$

The production functions and maximization problems of Foreign firms $f_{T F}^{*}$ and $f_{N}^{*}$ are the same as in the Home country. Note that only traded sector firms set two prices. Nontraded firms set only one price, for sales to their own domestic market.

Finally, the growth rate of technology for each country and sector follows an AR(1) process with an unconditional mean of zero.

\subsection{The solution of the model}

The rest of the paper focuses on a symmetric equilibrium, so all firms that can modify their price at date $t$ set the same price. The model is solved by log-linearising the equations around a deterministic equilibrium or steady state in which all the exogenous stochastic processes are set equal to their unconditional means, their variances are set to zero, and net foreign asset positions are normalised at zero. ${ }^{19}$

The steady-state terms of trade is not normalised to one but it is computed explicitly. It depends not only on the preference parameters but also on real factors, such as the unconditional means of the productivity processes. Three of these unconditional means are free parameters, which are calibrated so that in the steady state the ratio of Home to Foreign traded output is equal to one, and the Home and Foreign ratios of traded to nontraded output ${ }^{20}$ are equal to 0.2 .

An important feature of the solution is that individuals optimally choose to work a fixed workweek, i.e. $\mathbf{h}_{T H, t}$ and $\mathbf{h}_{N, t}$ are always constant and equal to each other. The adjustment in

\footnotetext{
${ }^{18}$ The aggregate labour input is given by the number of hours worked in the sector by each individual, times the measure of individuals working in that sector.

${ }^{19}$ No country is a net borrower or lender in the steady state, but international borrowing and lending occur in the short-run or transitional equilibrium path.

${ }^{20}$ In the US, the ratio of value added in manufacturing over the value added in services is approximately equal to 0.2. Source: own calculations based on the Groningen 60-Industry Database, http://www.ggdc.net.
} 
the labour inputs takes place exclusively through the extensive margin, i.e. the participation rates or probabilities. ${ }^{21}$

\section{Graphical analysis}

\subsection{Introduction and methodology}

In this Section I show that, after aggregating the equations of the model, the short-run transmission of shocks to the traded and nontraded sectors can be analysed with the aid of a simple Figure. Specifically, a system of three equations, (17), (19) and (20) can be used to illustrate the variables through which the shocks are propagated to sectoral output, employment and prices. ${ }^{22}$ Although some explanatory variables of this system are endogenous, it is not necessary to include more equations in the system for the purpose of explaining sectoral transmission, because only the knowledge of how the shocks affect the explanatory variables is required.

All the equations presented in this section describe the short-run equilibrium after a shock occurs at date $t$, under the assumption that in period $t-1$ the economy is at its steady state. I also assume that $\theta=1$, as this also simplifies the equations without limiting the analysis. ${ }^{23}$

\subsection{Definitions}

For any variable $X$, let $X_{0}$ denote the value of the variable at the deterministic equilibrium or steady state. Let $\widehat{X}_{t} \equiv \log \left(X_{t} / X_{0}\right) \simeq\left(X_{t}-X_{0}\right) / X_{0}$ denote the approximate short-run logdeviation from the initial steady state, and let $d X_{t} \equiv\left(X_{t}-X_{0}\right) / C_{0}$ denote instead the linear deviation, normalised with respect to steady-state consumption.

Total traded output is the sum of output sold at home and abroad:

\footnotetext{
${ }^{21}$ This happens for the following reason. From the Home individual maximization problem, by combining the first order condition with respect to $\mathbf{h}_{T H, t}$ with the first-order condition with respect to $n_{T H, t}$, we obtain:

$\kappa\left(\Gamma-\psi-\mathbf{h}_{T H, t}\right)-\kappa(\tau)=-\kappa^{\prime}\left(\Gamma-\psi-\mathbf{h}_{T H, t}\right) \mathbf{h}_{T H, t}$

Analogously, by combining the first order condition with respect to $\mathbf{h}_{N, t}$ with the first-order condition with respect to $n_{N, t}$, we obtain:

$\kappa\left(\Gamma-\psi-\mathbf{h}_{N, t}\right)-\kappa(\tau)=-\kappa^{\prime}\left(\Gamma-\psi-\mathbf{h}_{N, t}\right) \mathbf{h}_{N, t}$

It is then immediate to see that, at least for most commonly used functional forms, both the above two equations are satisfied when hours worked in the two sectors are constant and equal to each other, in the steady state and at each date $t$.

${ }^{22}$ The system illustrates the sectoral effects of the exogenous shocks because all the dependent variables are in ratios. For example, if the ratio $Y_{T H, t} / Y_{N}$ remains constant after a given shock occurs, then the responses of traded and nontraded output to the shock are identical. If, for example, $Y_{T H, t} / Y_{N}$ increases and both responses have positive sign, then we must deduce that the response of $\widehat{Y}_{T H, t}$ is larger than the response of $\widehat{Y}_{N}$.

${ }^{23}$ If $\theta$ is different from one then the parameter $\delta$ in equations (17) and (19) is replaced by the steady-state export share, which is increasing in $\delta$.
} 


$$
Y_{T H, t} \equiv Y_{T H, t}^{H}+Y_{T H, t}^{F}=C_{T H, t}+C_{T H, t}^{*}
$$

Traded sector firms set two different prices, one for domestic sales and one for exports. I define the price index for all Home traded goods as a weighted average of the prices set by the firms, with weights taken from the steady state:

$$
P_{T H, t}^{y} \equiv \frac{P_{T H, t} \cdot Y_{T H 0}^{H}+e_{t} P_{T H, t}^{*} \cdot Y_{T H 0}^{F}}{P_{T H 0} \cdot Y_{T H 0}^{H}+e_{0} P_{T H 0}^{*} \cdot Y_{T H 0}^{F}} .
$$

The terms of trade plays a crucial role in the transmission of shocks. It is defined as the price of Home imports over the price of Home exports:

$$
T_{t} \equiv \frac{P_{T F, t}}{e_{t} \cdot P_{T H, t}^{*}}
$$

\subsection{The relative supply}

First, an expression describing the evolution of inflation in the Home traded sector is derived from the first-order condition of the firm maximization problem. Then, by subtracting from that expression its counterpart for the Home nontraded sector ${ }^{24}$ we obtain:

$$
\begin{gathered}
\widehat{P}_{T H, t}^{y}-\widehat{P}_{N, t}=\delta(1-\zeta) \widehat{e}_{t} \\
+\beta E_{t}\left[\pi_{T H, t+1}^{y}-\pi_{N, t+1}-\delta(1-\zeta)\left(\widehat{e}_{t+1}-\widehat{e}_{t}\right)\right] \\
+\left(\frac{1-\varphi \beta}{1+\eta \frac{1-\alpha}{\alpha}} \frac{1-\varphi}{\varphi}\right)\left(\widehat{M C}_{T H, t}-\widehat{M C}_{N, t}\right),
\end{gathered}
$$

where $\pi_{T H, t+1}^{y} \equiv \widehat{P}_{T H, t+1}^{y}-\widehat{P}_{T H, t}^{y}$ denotes inflation in the traded sector, $\pi_{N, t+1} \equiv \widehat{P}_{N, t+1}-\widehat{P}_{N, t}$ denotes inflation in the nontraded sector, $M C_{T H}$ denotes real marginal cost in the traded sector:

$$
\widehat{M C}_{T H, t} \equiv \widehat{W}_{T H, t}-\widehat{P}_{T H, t}^{y}-\frac{1}{\alpha} \widehat{z}_{T H, t}+\frac{1-\alpha}{\alpha} \widehat{Y}_{T H, t}
$$

and $M C_{N}$ is analogously defined.

The relative output supply (17) describes how firms adjust the traded to nontraded output ratio $Y_{T H} / Y_{N}$ following changes in the relative price $P_{T H, t}^{y} / P_{N, t}$. It shows that short-run movements in the relative price depend on changes in the current and the expected future nominal

\footnotetext{
${ }^{24}$ The derivations of the equations are available in a separate Appendix.
} 
exchange rates, and the expectations of future inflation and real marginal cost differentials. ${ }^{25}$

Monetary shocks are transmitted to the relative supply (17) via changes in the nominal exchange rate and expected inflation differentials. The response of the relative price $P_{T H, t}^{y} / P_{N, t}$ to changes in the nominal exchange rate crucially depends on the degree of pass-through. If the pass-through is zero a depreciation of the Home currency in the current period (a positive $\widehat{e}_{t}$ ) has a positive effect on $P_{T H, t}^{y} / P_{N, t}$ (Equation 17). This happens because after a depreciation Home traded sector firms receive more Home currency for each unit of output sold abroad ${ }^{26}$ (Equation 15). However, an expected depreciation in the next period will have, ceteris paribus, an opposite effect on $P_{T H, t}^{y} / P_{N, t}$. In this case, Home traded sector firms know that in the next period they will receive more Home currency for each unit of exports, so today they increase their prices less.

Productivity shocks are transmitted to the relative supply (17) via changes in marginal costs. A positive productivity shock, for example, lowers firms' real marginal costs, and induces them to lower their prices. If the productivity shock and the resulting fall in the marginal cost are persistent, then expected future inflation, which appears on the right-hand side of Equation (17), also falls. Therefore, under a positive productivity shock in the traded sector the relative price falls, while the opposite happens under a positive productivity shock in the nontraded sector. $^{27}$

\subsection{The relative demand}

By manipulating the demands for traded and nontraded goods, and using the Foreign resource constraint to substitute out the demand for Home exports, we obtain:

$$
\widehat{Y}_{T H, t}-\widehat{Y}_{N, t}=-\phi\left(\widehat{P}_{T H, t}^{y}-\widehat{P}_{N, t}\right)+\delta(1-\phi) \widehat{T}_{t}+\delta k_{4} d B_{t}-k_{7} d G_{t}
$$

where $k_{4}$ and $k_{7}$ are positive coefficients computed from the steady state equations. Notice that if there were no imports $(\delta=0)$, and thus the economy was closed, then only the relative price and government expenditure would affect the demand relationship.

\footnotetext{
${ }^{25}$ The slope of the relative supply curve depends on $(1-\alpha) / \alpha$, the coefficient on output in Equation (18). If $\alpha<1$, the slope is positive because the marginal productivity falls with production, so firms charge higher prices to compensate for the fall in productivity.

${ }^{26}$ If $\zeta=0$ (local currency pricing) then $P_{T H, t}^{*}$ can be regarded as predetermined, therefore an increase in $e_{t}$ results in an increase in $P_{T H, t}^{y}$, as shown by Equation 15 .

${ }^{27}$ Notice that $\widehat{P}_{T H, t}^{y}$ and $\widehat{P}_{N, t}$ appear both on the left and on the right-hand side of equation (17), since they affect the two marginal costs. It is possible re-write equation (17) so that the price indexes are all on the left-hand side, but the analysis would stay unchanged.
} 
Equation (19) shows that, keeping everything else unchanged, when the relative price $P_{T H, t}^{y} / P_{N, t}$ increases the demand for $Y_{T H} / Y_{N}$ decreases. An increase in (Home) bond holdings relative to the steady state implies that the Foreign country is increasing consumption through debt, so there is more demand for Home exports and the traded-nontraded output ratio increases. Moreover, when government expenditure increases the traded-nontraded output ratio decreases, as there is more demand for nontraded goods.

The response of the traded-nontraded output ratio $Y_{T H} / Y_{N}$ to an increase (deterioration) in the terms of trade depends on the parameter $\phi$ (Equation 19). If $\phi$ is larger than one, the response is negative. This happens because if the terms of trade increases, the relative price of imports increases, resulting in an increase in the price of traded goods relative to nontraded goods, $P_{T} / P_{N}$. If the elasticity of substitution $\phi$ is greater than one, consumers substitute a large amount of traded goods with nontraded goods, resulting in fall in the demand for $Y_{T H} / Y_{N}$

The relative employment demand is found by a manipulation of the production functions in the two sectors:

$$
\widehat{n}_{T H, t}-\widehat{n}_{N, t}=\frac{1}{\alpha}\left(\widehat{Y}_{T H, t}-\widehat{Y}_{N, t}\right)-\frac{1}{\alpha}\left(\widehat{z}_{T H, t}-\widehat{z}_{N, t}\right)
$$

Equation (20) shows that the changes in $n_{T H, t} / n_{N}$ can be explained by changes in the traded-nontraded output ratio and by sectoral productivity shocks.

Equations (17) to (20) are represented in Figure 1. The shifts in these relationships jointly determine the short-run changes in the relative price $P_{T H, t}^{y} / P_{N}$, the traded-nontraded output ratio $Y_{T H, t} / Y_{N}$ and the traded-nontraded employment ratio $n_{T H, t} / n_{N, t}$ after a shock. Notice that while Home productivity and government expenditure shocks directly affect Equations (17) to (20), Home monetary shocks and all the Foreign shocks affect these relationships only indirectly, through their effect on the terms of trade and bond holdings (Equation 19), and on the current and the expected future nominal exchange rates and the expected sectoral inflation differential $^{28}$ (Equation 17).

\footnotetext{
${ }^{28}$ The Home and Foreign money demand and the Euler equations for consumption are the only equations that were left out in the derivation of Equations (17), (19) and (20). However, such omission does not weaken the analysis, since the transmission of shocks through intertemporal substitution and the interest rate is already captured by the change in bonds holdings in Equation (19). Therefore, the system is sufficient to capture all the variables through which the exogenous shocks are transmitted to the sectoral output, price and employment ratios.
} 
Figure 1: Relative price, output and employment
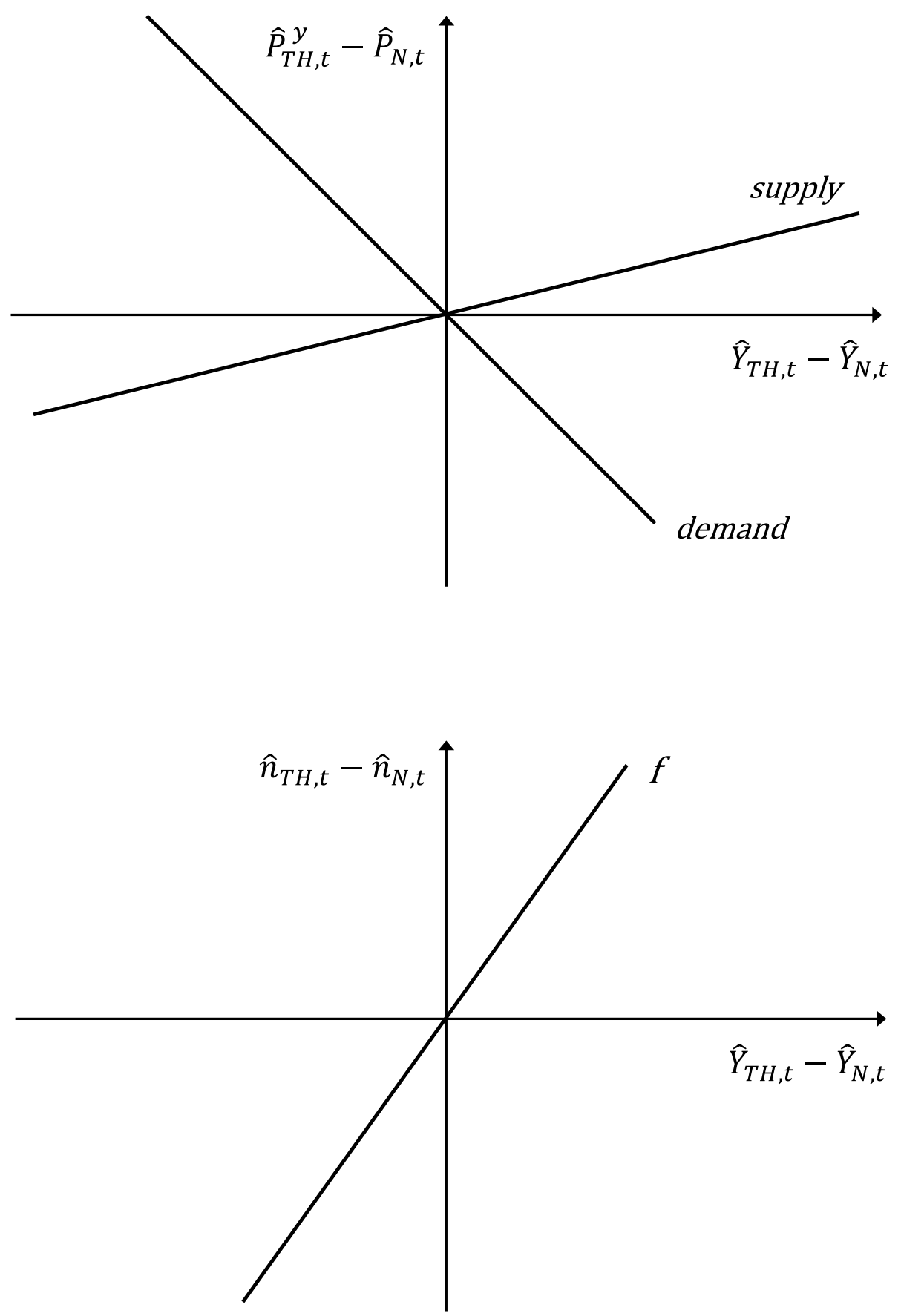
Table 1: Baseline parametrization

\begin{tabular}{llc}
\hline \hline Individual preferences and budget constraint: & \\
\hline$\beta$ & Discount factor & 0.99 \\
$\nu$ & Intermediation cost & 0.005 \\
$\sigma$ & Risk aversion for consumption & 5 \\
$\varepsilon$ & Risk aversion for real money balances & 5 \\
$\phi$ & Elasticity of substitution traded-nontraded goods & 1 or 0.74 \\
$\gamma$ & Weight of nontraded goods in total consumption & 0.7 \\
$\theta$ & Elasticity of substitution Home-Foreign traded goods & 1 \\
$\delta$ & Home bias parameter & 0.3 \\
\hline Production: & \\
\hline$\eta$ & Elasticity of substitution among differentiated goods & 7.88 \\
$\zeta$ & Pass-through elasticity & 0 or 1 \\
$\varphi$ & Probability of not changing prices & 0.75 \\
$\alpha$ & Elasticity of output with respect to hours & 0.8 \\
\hline \hline
\end{tabular}

\section{Numerical results}

The baseline parameters used in the computation of the impulse responses and in the simulations of the model are presented in Table 1 . The intermediation cost parameter $\nu$ is chosen so that the spread in the nominal interest rates approximates the value suggested by Benigno (2009). The consumption elasticity of money demand $(\sigma / \varepsilon)$ is commonly estimated to be unity, and the value of $\sigma$ is taken from Chari, Kehoe and McGrattan (2002). I set the elasticities of substitution $\phi$ and $\theta$ equal to one, and in Section $5.1 \mathrm{I}$ analyse whether the results change if $\phi$ and $\theta$ are different from one. The preference weight for nontraded goods $\gamma$ is set between the values suggested by Obstfeld and Rogoff (2007) and Benigno and Thoenissen (2003), and the parametrization of $\delta$, the preference weight for Foreign-produced traded goods, is as in Obstfeld and Rogoff (2005). ${ }^{29}$ The parameter $\eta$ implies that the steady state markup is about 1.15 , and the price adjustment parameter $\varphi$ is set such that the average price duration is one year. The parameter $\alpha$ is calibrated so that, given the mark-up, in the steady state the share of wages in total output is equal to 0.7 . Finally, the utility parameters $\kappa$ and $\psi$ are chosen so that hours worked in the steady state are equal to 0.24 .

\footnotetext{
${ }^{29}$ The calibrated value for $\delta$ implies that the share of imports over aggregate output is $5 \%$, which is roughly the share of the combined imports from Canada, Japan, Mexico, France, Germany and the UK over U.S. GDP.
} 


\subsection{Responses to monetary shocks}

Here I explain how to use the analytical framework of Section 4 to investigate how the passthrough elasticity and the other parameters of the model affect the transmission of monetary shocks to the two sectors.

Impulse responses to a $1 \%$ unexpected increase in the Home nominal money growth rate are presented in Figure 2. These have been derived under the baseline parametrization of Table 1, thus under the simplifying assumptions that the degree of price rigidity is the same in both sectors, and that the two substitution elasticities $\phi$ and $\theta$ are equal to one. ${ }^{30}$ Impulse responses under alternative parametrizations are concisely reported in Tables 2 and 3 and discussed separately.

The parameters of the model affect the short-run equilibrium conditions (17) and (19) in two ways. First, the model parameters enter Equations (17) to (19) directly, thus affecting the slope and the intercept of the relative supply and demand schedules. Secondly, the model parameters affect the responses of $\widehat{T}_{t}, d B_{t}$, the nominal exchange rate and expected inflation in the two sectors, therefore indirectly affecting the relative supply and demand schedules through their impact on the variables that are exogenous to the system of equations (17) to (19).

Figure 2 shows that a positive monetary shock causes a nominal depreciation and an increase in Home bond holdings. If $\zeta$ is equal to one, the exchange rate pass-through into import prices is full, so the currency depreciation causes an increase in the Home import price $P_{T F, t}$ plus a fall in the export price $P_{T H, t}^{*}$, and as a result the terms of trade increases (Equation 16). On the other hand, if $\zeta$ is equal to zero there is no exchange rate pass-through, thus the nominal depreciation causes the terms of trade to fall. Moreover, if $\zeta$ is equal to one the increase of Home traded output is bigger than the increase in nontraded output, but if $\zeta$ is equal to zero the increase of Home traded output is smaller than the increase in nontraded output.

The impulse responses of Figure 2 can be understood by means of Figure 3, which illustrates how the supply (17) and demand (19) shift after a positive shock to the Home money growth rate. The relative output demand (19) shifts up because Home bond holdings become positive. Since both sectors have the same degree of price stickiness, the difference between the expected future inflation rates in the two sectors is very small, moreover, with this parametrization there

\footnotetext{
${ }^{30}$ The assumption $\theta=1$ was used in the derivation of Equations (17) to (19), and the assumption $\phi=1$ ensures that changes in the terms of trade have no effect on the relative output demand (19).
} 
Figure 2: Impulse responses to a $1 \%$ Home monetary shock, baseline parametrization and $\phi=1$
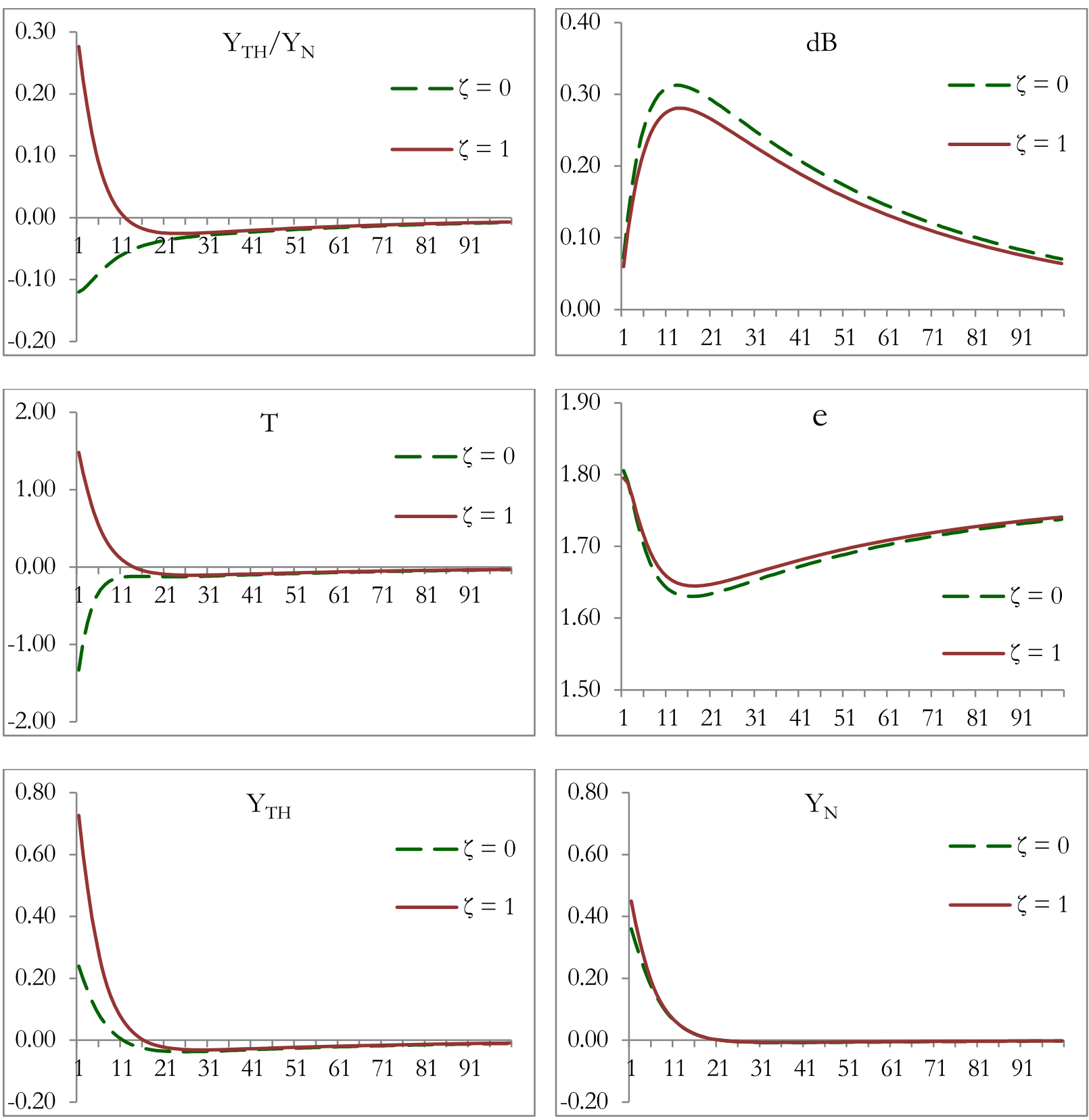

Note: Responses are percentage deviations from steady state values, except for bond holdings, which are linear deviations. Time is in quarters. 
is only a mild exchange rate overshooting. Therefore, the most significant variable on the righthand side of the relative supply curve (17) is the nominal exchange rate depreciation at time $t$. The pass-through elasticity $\zeta$ determines the size of the shift of the relative supply curve. If $\zeta$ is equal to one (full pass-through), then the exchange rate drops from the right-hand side of Equation (17), which implies that the relative supply curve does not shift after a monetary shock. Therefore, the short-run equilibrium is point $B$ in Figure 3: there is a stronger response of the traded-nontraded output ratio and a modest increase in the relative price. If $\zeta$ is lower than one (incomplete pass-through), then the relative supply curve shifts upwards, as a result there is a larger increase in the relative price and a smaller increase of the traded-nontraded output ratio than if $\zeta=1$ (point $A$ ). The lower is $\zeta$, and the higher is the upward shift of the relative supply curve (17) after a monetary shock. In the limiting case of zero pass-through, the increase in the relative price is so pronounced that the traded-nontraded output ratio falls in the short-run. Point $C$ in Figure 3 is the short-run equilibrium after a monetary shock if $\zeta$ is equal to zero.

To check the robustness of these results I compute the impulse responses under alternative assumptions about the other parameter values (Tables 2 and 3). For each of the two elasticities of substitution in consumption I consider the two symmetric values of 0.5 and 1.5 , since most of the values used in the literature lie within or close to this range. ${ }^{31}$ Both elasticities may change the response of the traded-nontraded output ratio: $\phi$ affects the slope and the intercept of the relative demand (19), and $\theta$ affects the response of bond holdings. According to Tables 2 and 3 , the result that traded sector output responds more to monetary shocks if the passthrough elasticity is equal to one, but responds less if the pass-through elasticity is zero, is generally robust to changes in $\phi$ and $\theta$. Only in the case of $\theta=0.5$ the short-run response of nontraded output is above the response of traded output, regardless of the degree of passthrough. However, empirical estimates of $\theta$ do not indisputably suggest that it should be well below one, instead, there is considerable uncertainty regarding the value of trade elasticities. ${ }^{32}$

The parameter $\delta$ may also affect the result since it directly enter into the Equations (17) and (19). Most papers in the literature assume home bias in consumption, therefore $\delta$ is normally

\footnotetext{
${ }^{31}$ For example, Obstfeld and Rogoff (2005) consider a value of 2 for the elasticity of substitution between traded and nontraded goods $\phi$, but they cite empirical estimates as low as 0.44. Corsetti, Dedola and Leduc (2008) consider both values of 0.5 and 1.5 for the elasticity of substitution between Home and Foreign traded goods $\theta$.

${ }^{32}$ Estimates of $\theta$ based on aggregated data suggest values lower than one, while estimates based on disaggregated data suggest much larger values. Explanations of such discrepancies have pointed to the problem of the aggregation bias (Obstfeld and Rogoff 2005).
} 
Figure 3: Sectoral effects of monetary shocks

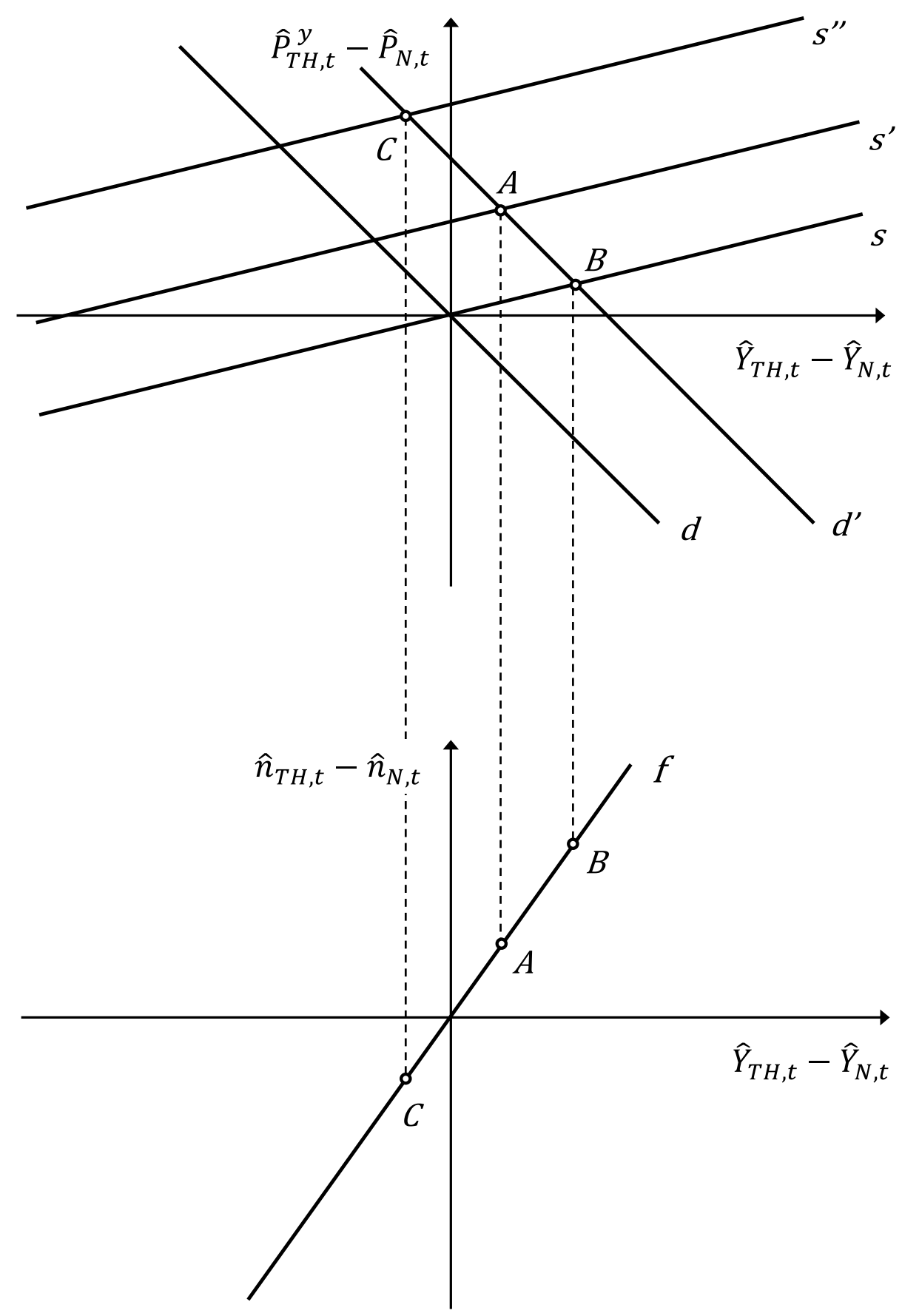


Table 2: Responses to a Home monetary shock, $\zeta=0$

\begin{tabular}{c|c|c|c|c|c|c|c|c}
\hline \hline$t$ & Baseline & $\theta=0.5$ & $\theta=1.5$ & $\delta=0.1$ & $\delta=0.4$ & $\phi=0.5$ & $\phi=1.5$ & $\begin{array}{c}\text { Het. price } \\
\text { rigidity }\end{array}$ \\
\hline & & & \multicolumn{7}{c}{ Response of $Y_{T H}$} \\
1 & 0.239 & 0.229 & 0.247 & 0.314 & 0.198 & 0.248 & 0.230 & 0.019 \\
5 & 0.099 & 0.079 & 0.106 & 0.155 & 0.064 & 0.113 & 0.076 & -0.431 \\
21 & -0.036 & -0.038 & -0.045 & -0.005 & -0.053 & -0.043 & -0.041 & -0.238 \\
\hline & \multicolumn{8}{|c}{ Response of $Y_{N}$} \\
1 & 0.360 & 0.358 & 0.359 & 0.352 & 0.361 & 0.353 & 0.373 & 0.565 \\
5 & 0.193 & 0.181 & 0.193 & 0.181 & 0.194 & 0.182 & 0.208 & 0.580 \\
21 & 0.001 & -0.015 & 0.002 & 0.007 & -0.003 & 0.004 & -0.013 & 0.161 \\
\hline \hline
\end{tabular}

Note: Responses are percent deviations from steady state values at quarters 1,5 and 21 . The baseline parametrization is shown in Table $1, \phi=1$. The other specifications differ from the baseline only with respect to the parameters indicated at the top of each column. In the last column ("Heterogeneous price rigidity") $\varphi_{T H}=\varphi_{T F}^{*}=0.559$ and $\varphi_{N}=\varphi_{N}^{*}=0.890$. The AR parameters of the exogenous processes are in Table 4.

Table 3: Responses to a Home monetary shock, $\zeta=1$

\begin{tabular}{c|c|c|c|c|c|c|c|c}
\hline \hline$t$ & Baseline & $\theta=0.5$ & $\theta=1.5$ & $\delta=0.1$ & $\delta=0.4$ & $\phi=0.5$ & $\phi=1.5$ & $\begin{array}{c}\text { Het. price } \\
\text { rigidity }\end{array}$ \\
\hline & & & & \\
1 & 0.727 & 0.442 & 0.972 & 0.494 & 0.818 & 0.802 & 0.649 & 0.430 \\
5 & 0.319 & 0.220 & 0.383 & 0.230 & 0.353 & 0.359 & 0.270 & -0.344 \\
21 & -0.024 & 0.015 & -0.061 & -0.002 & -0.033 & -0.020 & -0.030 & -0.238 \\
\hline & \multicolumn{8}{c}{ Response of $Y_{N}$} \\
1 & 0.450 & 0.461 & 0.443 & 0.382 & 0.482 & 0.400 & 0.568 & 0.632 \\
5 & 0.215 & 0.228 & 0.208 & 0.186 & 0.228 & 0.195 & 0.253 & 0.583 \\
21 & 0.001 & 0.014 & -0.003 & 0.006 & -0.001 & 0.006 & -0.014 & 0.161 \\
\hline \hline
\end{tabular}

Note: See Table 2.

calibrated below 0.5 . In the baseline parametrization, $\delta$ is equal to the ratio of imports of goods over total expenditure on goods. I consider two alternative values ${ }^{33}, \delta=0.1$ and $\delta=0.4$. Tables 2 and 3 show that the result that trade openness increases the output sensitivity to monetary shocks when $\zeta=1$, but decreases it when $\zeta=0$, is robust to changes in $\delta$.

Bouakez, Cardia and Ruge-Murcia (2009) find evidence of substantial heterogeneity in price rigidity across sectors, moreover, they show that such heterogeneity is crucial to understand the sectoral responses to monetary shocks. In order to investigate how heterogeneity in price rigidity affects the sectoral responses to monetary shocks, I relax the assumption that the two

\footnotetext{
${ }^{33}$ The ratio of imports of goods over total expenditure on goods is roughly $35 \%$ in the US.
} 
sectors have the same degree of price rigidity. ${ }^{34}$ Specifically, I set $\varphi_{T H}=\varphi_{T F}^{*}=0.559$ and $\varphi_{N}=\varphi_{N}^{*}=0.890$, which are the Bouakez, Cardia and Ruge-Murcia's implied estimates of the probabilities of not changing prices in the nondurable manufacturing and the service sectors, respectively. ${ }^{35}$ The assumption that prices are more flexible in the traded sector affects the result significantly: now nontraded output responds more than traded output to monetary shocks not only when the pass-through elasticity is zero, but also when it is one (Tables 2 and 3). However, this finding is also due to the relatively high $(\phi=1)$ elasticity of substitution between traded and nontraded goods. Since lower values are more common in the literature, I depart from this simplifying assumption in the next Section.

In summary, the results of Tables 2 and 3 show that the most important factors which affect the role of trade openness in the transmission of monetary shocks are exchange rate pass-through and heterogeneity in price setting. If the two sectors have the same degree of price rigidity, the role of trade openness in the monetary transmission can be completely reversed according to the degree of exchange rate pass-through. If the traded sector has more flexible prices, trade openness does not increase (and it may decrease) the sensitivity of output to monetary shocks. The other parameters also affect the results, but not as significantly, therefore altering the response of the traded-nontraded output ratio by means of the other parameters would require a strong departure from the baseline parametrization. Given the high sensitivity of the response of the traded-nontraded output ratio to the pass-through elasticity $\zeta$ and the Calvo parameters $\varphi_{T H}$ and $\varphi_{N}$, these offer the most likely explanation of the conflicting findings of the empirical literature. However, note that not all the studies analyse the response of the manufacturing and service sectors to monetary shocks, so both assumptions of homogeneous and heterogeneous price rigidity are useful to understand the empirical literature.

\subsection{Analysis on simulated data}

In this Section I use simulated data from the model to construct concise measures of the impact of monetary shocks on sectoral output. The methodology I use is close to the reduced-form approach of the empirical literature. Here I depart from the simplifying assumption that the elasticity of substitution between traded and nontraded goods is equal to one. Instead, I set

\footnotetext{
${ }^{34}$ The assumption that the degree of price rigidity is the same in both sectors is crucial in the derivation of Figure 1. In the case of sectoral price heterogeneity, it is not possible to analyse the responses of traded and nontraded output by means of a simple figure.

${ }^{35}$ These values imply an average price duration of about seven months in the traded sector, and two years and three months in the nontraded sector.
} 
Table 4: Parameters of exogenous processes used in the simulations

\begin{tabular}{ll}
\hline \hline Exogenous processes: $\widehat{x}_{t}=\bar{x}+\rho \cdot \widehat{x}_{t-1}+\epsilon$ \\
\hline Home money growth & $\rho=0.4355, \operatorname{var}(\epsilon)=(0.0093)^{2}$ \\
Foreign money growth & $\rho=0.3473, \operatorname{var}(\epsilon)=(0.0081)^{2}$ \\
Home traded goods technology & $\rho=0.8263, \operatorname{var}(\epsilon)=(0.0080)^{2}$ \\
Foreign traded goods technology & $\rho=0.8312, \operatorname{var}(\epsilon)=(0.0098)^{2}$ \\
Home nontraded goods technology & $\rho=0.8264, \operatorname{var}(\epsilon)=(0.0035)^{2}$ \\
Foreign nontraded goods technology & $\rho=0.5799, \operatorname{var}(\epsilon)=(0.0047)^{2}$ \\
Home government expenditure & $\rho=0.6746, \operatorname{var}(\epsilon)=(0.0012)^{2}$ \\
Foreign government expenditure: & $\rho=0.6449, \operatorname{var}(\epsilon)=(0.0015)^{2}$ \\
\hline \hline
\end{tabular}

$\phi=0.74$, following Corsetti, Dedola and Leduc (2008). ${ }^{36}$ The other model parameters stay as in the baseline parametrization of Table 1.

I generate artificial time series by simulating the model over 5,500 periods and discarding the first 500 observations. The shocks used to simulate the model are estimated by fitting AR(1) processes to the time series of the money growth rates and the logs of technology and government expenditures, under the assumption that all the cross-correlations between the shocks to the exogenous processes are equal to zero. The standard deviations and autocorrelation parameters of the exogenous processes ${ }^{37}$ are reported in Table 4 . In each simulation I change the elasticity of exchange rate pass-through or the degree of price rigidity, but I keep the same sequence of random draws. The simulated series are detrended using the HP-filter. ${ }^{38}$

The analysis on simulated data differs from the impulse response analysis of Section 5.1 because the artificial data has been obtained using a comprehensive menu of shocks. In particular, the inclusion of technology shocks improves the persistence of output in the simulated series. Figure 4 reports the autocorrelation functions of traded and nontraded output under alternative assumptions about exchange rate pass-through and sectoral price rigidity. The autocorrelation functions of traded output generated by the model match reasonably well their empirical counterpart, under both zero and full pass-through. However, the model struggles to match the comparatively higher persistence of nontraded output at lags $5-11$, even with higher price rigidity in the nontraded goods sector.

\footnotetext{
${ }^{36}$ This value for $\phi$ is roughly the average between $\phi=0.44$ as estimated by Stockman and Tesar (1995) and $\phi=1$ as suggested by Obstfeld and Rogoff (2005).

${ }^{37}$ The data used in the estimation of the exogenous processes is described in a separate Appendix.

${ }^{38}$ The smoothing parameter is 1,600 .
} 
Figure 4: Autocorrelations in the data and in the simulated series, baseline parametrization and $\phi=0.74$

\section{a) Identical price rigidity}
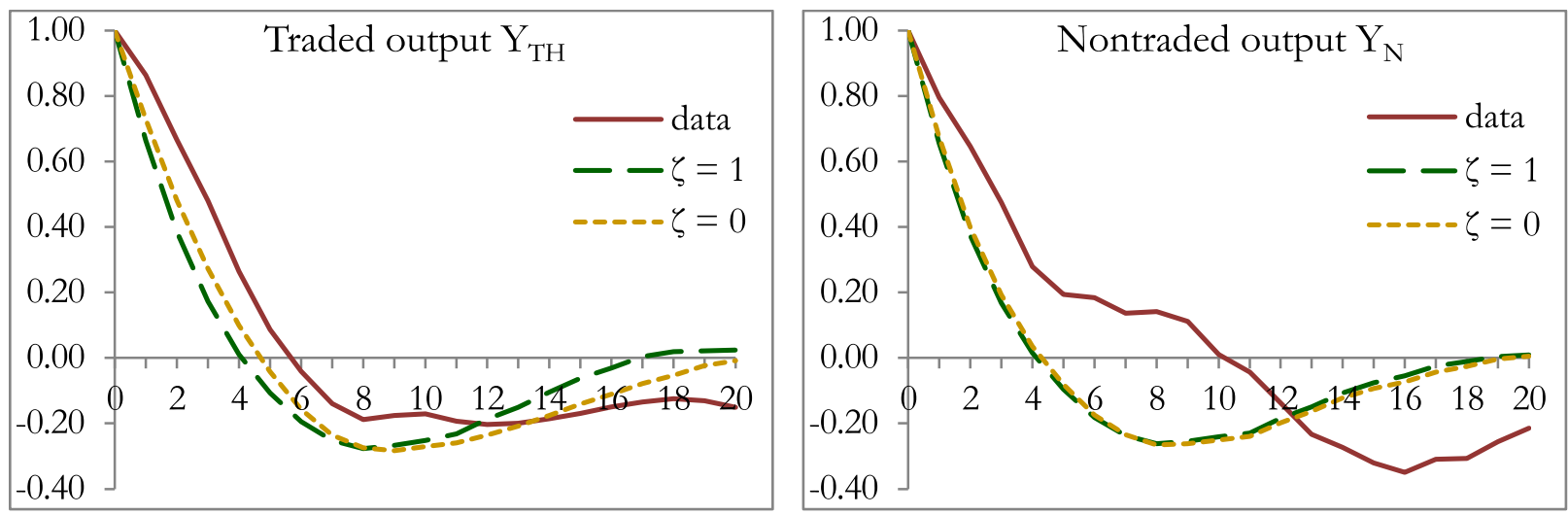

\section{b) Heterogeneous price rigidity}
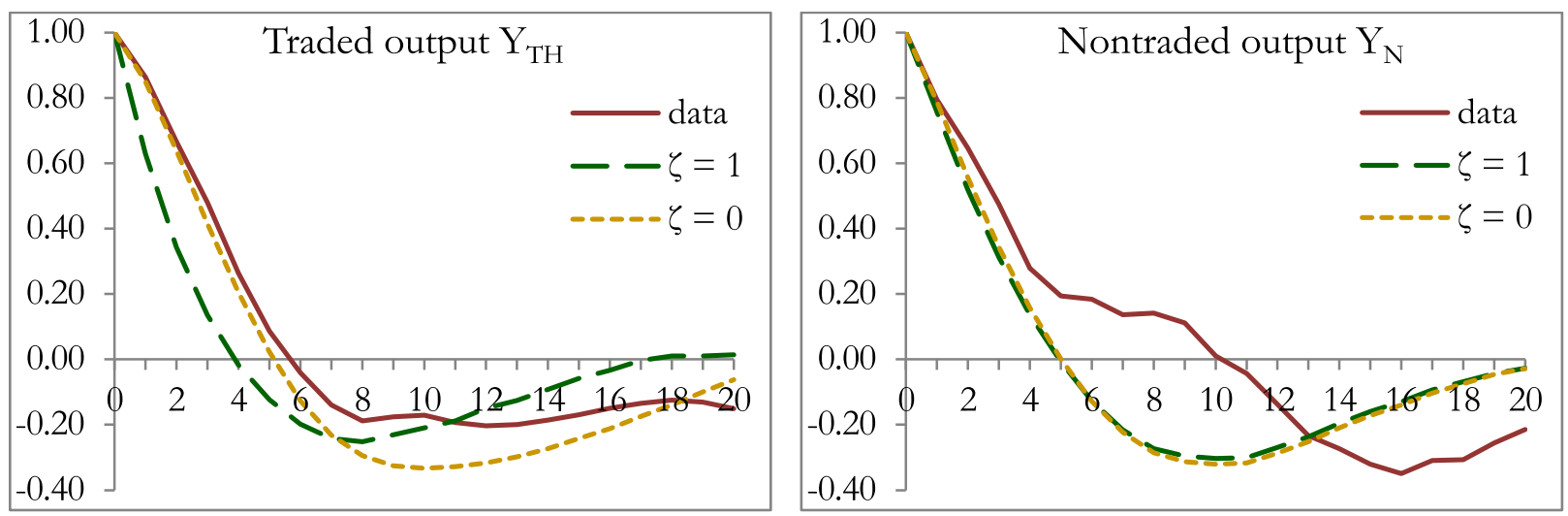

Note: Time is in quarters. 
I measure the impact of monetary shocks on traded and nontraded output by adapting the regression approach of Peersman and Smets (2005) to my setup. Specifically, I fit to the artificial time series the following two equations:

$$
\begin{gathered}
\widehat{Y}_{T H, t}=\kappa_{T H, 1} \widehat{Y}_{T H, t-1}+\kappa_{T H, 2} \widehat{Y}_{T H, t-2}+\lambda_{T H} M P_{t}+\varepsilon_{T H, t} \\
\widehat{Y}_{N, t}=\kappa_{N, 1} \widehat{Y}_{N, t-1}+\kappa_{N, 2} \widehat{Y}_{N, t-2}+\lambda_{N} M P_{t}+\varepsilon_{N, t}
\end{gathered}
$$

where $M P$ is the actual series of i.i.d. shocks to the money growth rate used in the simulations of the model. The coefficients $\lambda_{T H}$ and $\lambda_{N}$ can be interpreted as the estimates that would result from a reduced form approach, under the assumption that the data is generated by the same DGP as the model economy. I compute $\lambda_{T H}$ and $\lambda_{N}$ by fitting Equations (21) and (22) above to the simulated data by means of the Generalized Method of Moments (GMM) approach, using all the left-hand side variables and a constant as the instruments. ${ }^{39}$ The GMM estimates and the minimized value of the objective function are reported in Table 5. The coefficients $\lambda_{T H}$ and $\lambda_{N}$ have the expected signs, namely an increase in the money growth rate has a positive effect on output.

The specification (21)-(22) differs from Peersman and Smets' (2005) in a few respects. First, consistently with my model, I define monetary shocks as innovations to the money growth rates, while they use the contribution of the monetary policy shocks to the interest rate. ${ }^{40}$ Secondly, they measure monetary shocks using a VAR, under the identifying assumption that monetary policy shocks do not have a contemporaneous impact on output and prices. But since the impulse responses from my model show that monetary shocks have a strong immediate effect on output, I use contemporaneous shocks rather than lagged shocks on the left-hand side of Equations (21) and (22), and I check that the monetary policy shocks are not contemporaneously correlated with the residuals. Finally, I measure output as the log-linear deviation from its steady state value, while Peersman and Smets (2005) measure it as the growth rate of industrial production.

We can analyse the role of trade openness by comparing the coefficients $\lambda_{T H}$ and $\lambda_{N}$. Table

\footnotetext{
${ }^{39}$ The optimal weighting matrix is computed using the Newey and West (1987) estimator with a Bartlett kernel.

${ }^{40}$ In this model the same monetary policy can be specified by either an interest rate rule or a money supply rule (see for example Galí, 2015 for a discussion of models with money in the utility function). From an empirical point of view, the advantages of using the nominal stock of money to measure monetary policy shocks are discussed in Kasumovich and Fung (1998). The assumption that the money supply is exogenous is advantageous from a modelling perspective, because the results do not depend on the calibration of the parameters of the interest rate rule.
} 
Table 5: The sectoral effects of money shocks

\begin{tabular}{l|cc|cc}
\hline \hline \multirow{2}{*}{} & \multicolumn{3}{|c}{ (a) Identical price rigidity } \\
\cline { 2 - 5 } & \multicolumn{2}{|c|}{$\zeta=0$} & \multicolumn{2}{c}{$\zeta=1$} \\
\hline \multirow{3}{*}{ Coefficient } & $\lambda_{T H}$ & $\lambda_{N}$ & $\lambda_{T H}$ & $\lambda_{N}$ \\
Std. Error & 0.250 & 0.359 & 0.773 & 0.446 \\
P-value & $(0.002)$ & $(0.002)$ & $(0.005)$ & $(0.002)$ \\
R-squared & $0.000)$ & $(0.000)$ & $(0.000)$ & $(0.000)$ \\
J-stat & $4.96 \mathrm{E}-07$ & $7.97 \mathrm{E}-07$ & $3.22 \mathrm{E}-07$ & $6.01 \mathrm{E}-07$ \\
\hline \hline & \multicolumn{3}{|c|}{$(\mathrm{b})$ Heterogeneous price rigidity } \\
\cline { 2 - 5 } & \multicolumn{2}{|c}{$\zeta=0$} & \multicolumn{2}{c}{$\zeta=1$} \\
\hline & $\lambda_{T H}$ & $\lambda_{N}$ & $\lambda_{T H}$ & $\lambda_{N}$ \\
Coefficient & 0.157 & 0.547 & 0.616 & 0.612 \\
Std. Error & $(0.003)$ & $(0.002)$ & $(0.005)$ & $(0.002)$ \\
P-value & $(0.000)$ & $(0.000)$ & $(0.000)$ & $(0.000)$ \\
R-squared & 0.837 & 0.979 & 0.833 & 0.975 \\
J-stat & $3.59 \mathrm{E}-08$ & $1.76 \mathrm{E}-06$ & $2.33 \mathrm{E}-07$ & $1.50 \mathrm{E}-06$ \\
\hline \hline
\end{tabular}

5(a) shows that, in the case of identical price rigidity, if the pass-through is zero $(\zeta=0)$ trade openness reduces the impact of monetary shocks on output. On the other hand, if the passthrough is full $(\zeta=1)$, then trade openness amplifies the output response to monetary shocks. Hence, empirical estimates of the role of trade openness in the transmission of monetary shocks may lead to very different conclusions, depending on the degree of exchange rate pass-through. It is also possible to find some intermediate pass-through elasticity such that the responses to a monetary shock are equalized between the two sectors. Under this parametrization, if $\zeta$ is equal to 0.2491 , then the coefficients $\lambda_{T H}$ and $\lambda_{N}$ are not significantly different. ${ }^{41}$

In order to investigate how heterogeneity in price rigidity interacts with the pass-through elasticity, I generate additional simulated series under the assumption that nontraded goods prices are more rigid than traded goods prices, while keeping all the other structural parameters and shocks processes unchanged, and I re-calculate the coefficients $\lambda_{T H}$ and $\lambda_{N}$. Table 5(b) illustrates the strong impact of the elasticity of exchange rate pass-through, even when there is a considerable difference in the degree of price stickiness in the two sectors. The output response to a monetary shock should be higher in the sector with the most rigid prices, which is the nontraded sector. This is true only as long as the degree of pass-through is not complete. If the

\footnotetext{
${ }^{41}$ To put this value in perspective, Goldberg and Campa (2010) estimate that import price elasticities range from 0.38 (Sweden) to 1.08 (Portugal). However, they also find smaller, but not statistically significant, estimates in several countries.
} 
pass-through is full, then a positive monetary shock causes an increase in the terms of trade and an expenditure-switching effect that results in a strong increase of traded output, so that the traded and nontraded output responses are basically equalized. By examining Table 5(b) we can also infer that, if prices are more rigid in the nontraded sector, then it is not possible to find a positive correlation between trade openness and the sensitivity of output to monetary shocks. This result does not imply that trade openness does not increase the sensitivity of output to monetary shocks, since it is a consequence of heterogeneous price setting.

The results from the analysis on simulated data can rationalize the lack of conclusive empirical evidence on the role of trade openness in the transmission of monetary shocks. Notice however that different studies use different methodologies, and almost all the studies which were summarized in Section 2 do not report the response of the traded-nontraded price ratio after a shock. ${ }^{42}$ Thus, since we do not have information on the degree of sectoral price rigidity in each study, both sets of results (for identical and heterogeneous price rigidity) can offer an interpretation of the empirical findings on a case-by-case basis.

For example, some authors analyse the sectoral effects of monetary shocks by focusing on manufacturing or industry-level data. In this case there is no prima facie evidence that the less open sectors have more rigid prices, as it may instead happen when both manufacturing and services are included in the dataset. Moreover, because sectors belong to the same industrial classification, differences in price setting may not be very large, thus the assumption of identical price rigidity can be regarded as a useful approximation. ${ }^{43}$ Table 5 (a) shows that, if the pass-trough elasticity is relatively high, trade openness increases the sensitivity of output to monetary shocks, as found in one of the empirical studies (e.g. Hayo and Uhlenbrock 2000). However, for some intermediate value of the pass-through elasticity, the responses of traded and nontraded output to monetary shocks are equalized, thus explaining why some authors (Dedola and Lippi 2005, Peersman and Smets 2005) have found that trade openness does not matter in the transmission of monetary shocks.

Other authors study the sectoral effects of monetary shocks by examining a broader range of

\footnotetext{
${ }^{42}$ Among the studies surveyed in Section 2, only Hayo and Uhlenbrock (2000) analyse the response of the relative price ratio to monetary shocks. They find no statistically significant relationship between openness and the relative price response. This finding is consistent with the model presented in this paper, provided that the two sectors have similar or identical price rigidity, the pass-through elasticity is one, and $\alpha$ is equal to or close to one.

${ }^{43}$ The model can be used to rationalize the empirical findings based upon industry-level data because the notion of tradedness is always operationalized by deciding on an arbitrary threshold for the proportion of output that is actually traded. Therefore it is always possible to classify some manufacturing sectors as traded (nontraded) if the percentage of their output that is traded is above (below) a certain threshold.
} 
sectors, and they include both manufacturing and services in their dataset. Since the evidence (Bouakez, Cardia and Ruge-Murcia 2009) suggests that services have more rigid prices than manufacturing, in these studies some of the sectors which have more rigid prices are the less open (i.e. price rigidity might be negatively correlated with openness in their dataset). Thus, Table 5(b) may be more relevant to this set of empirical findings. However, it is important to note that in the sectoral data there is no dichotomy between traded and nontraded sectors, as in the model, since in any sector there are goods that are actually traded and goods that are not traded. Consequently, the model may offer an interpretation of the findings of the empirical literature, but it is not possible to conduct a quantitative comparison.

Table 5(b) shows that when price rigidity is negatively correlated with openness and the passthrough elasticity is below one, nontraded output responds more to monetary shocks than traded output. This result may cast another light on the findings of Ganley and Salmon (1997) and Arnold (2013), who find that some nontraded sectors (such as construction) are more sensitive than manufacturing to monetary shocks. These authors suggest that this might happen because the demand for some service goods is more interest-sensitive than the demand for manufacturing goods. Table 5(b) suggests a different explanation based upon price rigidity at the sectoral level, which may complement other explanations offered by the literature.

While the results of Table 5(b) are consistent with some of the empirical findings, they are at odds with other. A few authors (Farès and Srour 2001, Doyle, Erceg and Levin 2005, Llaudes 2007) have found that manufacturing responds more to monetary shocks that services. However, if price rigidity is negatively correlated with openness, a standard New Keynesian model cannot replicate a positive relationship between the impact of monetary shocks on output and the degree of openness ${ }^{44}$ regardless of the elasticity of exchange rate pass-through (Table $5(\mathrm{~b})$ ). Future empirical work may shed light on this puzzle by analysing the relationship between sectoral price rigidity and openness.

On the other hand, it would be incorrect to deduce from Table 5(b) that trade openness reduces the sensitivity of output to monetary shocks under heterogeneous price rigidity. This is because in order to understand the role of trade openness it is necessary to conduct a ceteris paribus analysis. But if the sectors have different degrees of price rigidity, they differ in one important characteristic that may be empirically correlated with openness. Indeed the results from the model suggest that ignoring sectoral heterogeneity in price rigidity can lead to an

\footnotetext{
${ }^{44}$ This would require a strong departure from the baseline parametrization, for example a very low value of $\phi$.
} 
incorrect assessment of the role of trade openness in the transmission of monetary shocks.

\section{Conclusion}

This paper shows that a standard New Keynesian open economy model can reproduce a positive, a neutral and even a negative relationship between openness to trade and the sensitivity of output to monetary shocks, thus rationalizing the range of results found in the empirical literature. This result is due to the crucial role played by both the pass-through elasticity and the sector-specific degree of price rigidity, which are generally not accounted for in the related empirical literature.

There are a few limitations of this analysis. Direct quantitative comparisons with the data are not possible because in any sector there are goods that are actually traded and goods that are not traded. Not all empirical findings can be replicated, and results from the model under heterogeneous price rigidity suggest an interesting puzzle for future research. In spite of these limitations, the model explains why the role of trade openness in the transmission of monetary shocks might have been incorrectly assessed.

The results from the model highlight the importance of controlling for the degree of exchange rate pass-through and the sector-specific amount of price rigidity in an empirical investigation of the sectoral effects of monetary shocks. By doing so we might find more detailed evidence on the actual role of international trade in the transmission of shocks, or find new empirical regularities that challenge the existing models. 


\section{$7 \quad$ References}

Arnold, Ivo J.M. (2013). "The Industry Effects of Monetary Policy and Their Welfare Implications." BNL Quarterly Review, Banca Nazionale del Lavoro, vol. 53(214), pages 287315.

Arnold, Ivo J. M., and Evert B. Vrugt. (2004). "Firm Size, Industry Mix and the Regional Transmission of Monetary Policy in Germany". German Economic Review, vol. 5(1), pages $35-59,02$.

Bank of England (1999). "The Transmission Mechanism of Monetary Policy". Bank of England Quarterly Bulletin, vol. 30(2), May.

Benigno, Pierpaolo. (2009). "Price Stability with Imperfect Financial Integration". Journal of Money, Credit and Banking, vol. 41(s1), pages 121-149.

Benigno, Gianluca, and Christoph Thoenissen. (2003). "Equilibrium Exchange Rates and UK Supply Side Performance". Economic Journal, vol. 113(486), pages C103-C124.

Betts, Caroline M., and Michael B. Devereux. (1996). "The Exchange Rate in a Model of Pricing-to-Market." European Economic Review, vol. 40(3-5), pages 1007-1021.

Betts, Caroline M., and Michael B. Devereux. (2000). "Exchange Rate Dynamics in a Model of Pricing-to-Market." Journal of International Economics, vol. 50(1), pages 215-244.

Betts, Caroline M., and Timothy J. Kehoe. (2001). "Tradability of Goods and Real Exchange Rate Fluctuations". Manuscript, University of Southern California and University of Minnesota.

Bouakez, Hafedh, Emanuela Cardia, and Francisco J. Ruge-Murcia. (2009). "The Transmission Of Monetary Policy In A Multisector Economy." International Economic Review, vol. 50(4), pages 1243-1266.

Burnside, Craig, Martin Eichenbaum, and Sergio Rebelo. (1993). "Labor Hoarding and the Business Cycle." Journal of Political Economy, vol. 101(2), pages 245-273.

Calvo, Guillermo A. (1983). "Staggered prices in a utility-maximizing framework." Journal of Monetary Economics, vol. 12(3), pages 383-398.

Carlino, Gerald, and Robert Defina. (1998). "The Differential Regional Effects Of Monetary Policy". The Review of Economics and Statistics, vol. 80(4), pages 572-587.

Chari, V. V., Patrick J. Kehoe, and Ellen R. McGrattan. (2002). "Can Sticky Price Models Generate Volatile and Persistent Real Exchange Rates?" Review of Economic Studies, vol. 
69(3), pages 533-563.

Corsetti, Giancarlo, Luca Dedola and Sylvain Leduc. (2008). "High Exchange-Rate Volatility and Low Pass-Through". Journal of Monetary Economics, vol. 55(6), pages 1113-1128.

Corsetti, Giancarlo, and Paolo Pesenti. (2001). "Welfare and Macroeconomic Interdependence". The Quarterly Journal of Economics, vol. 116(2), pages 421-445.

Corsetti, Giancarlo, and Paolo Pesenti. (2005). "International Dimensions of Optimal Monetary Policy." Journal of Monetary Economics, vol. 52(2), pages 281-305.

Dedola, Luca, and Francesco Lippi. (2005). "The Monetary Transmission Mechanism: Evidence from the Industries of Five OECD Countries". European Economic Review, vol. 49(6), pages 1543-1569.

Dotsey, Michael, and Margarida Duarte. (2008). "Nontraded Goods, Market Segmentation, and Exchange Rates". Journal of Monetary Economics, vol. 55(6), pages 1129-1142.

Doyle, Brian M., Christopher J. Erceg, and Andrew T. Levin. (2005). "Monetary Policy Rules in Economies with Traded and Non-Traded Goods." Unpublished manuscript.

Duarte, Margarida, and Maurice Obstfeld. (2008). "Monetary Policy in the Open Economy Revisited: The Case for Exchange-Rate Flexibility Restored". Journal of International Money and Finance, vol. 27(6), pages 949-957.

European Central Bank. (2011). "The Monetary Policy of ECB". Frankfurt am Main: The European Central Bank, third edition.

Farès, Jean, and Gabriel Srour. (2001). "The Monetary Transmission Mechanism at the Sectoral Level". Working Papers 01-27, Bank of Canada.

Fung, Ben Siu-cheong, and Marcel Kasumovich. (1998). "Monetary shocks in the G-6 countries: Is there a puzzle?" Journal of Monetary Economics, vol. 42(3), pages 575-592.

Galí, Jordi (2015). "Monetary Policy, Inflation, and the Business Cycle: An Introduction to the New Keynesian Framework and Its Applications." Second edition. Princeton: Princeton University Press.

Ganley, Joe, and Chris Salmon. (1997). "The Industrial Impact of Monetary Policy Shocks: Some Stylised Facts". Bank of England working papers 68, Bank of England.

Georgiadis, Georgios. (2015). "Examining Asymmetries in the Transmission of Monetary Policy in the Euro Area: Evidence from a Mixed Cross-Section Global VAR Model". European Economic Review, vol. 75(C), pages 195-215.

Goldberg, Linda S., and José Manuel Campa. (2010). "The Sensitivity of the CPI to 
Exchange Rates: Distribution Margins, Imported Inputs, and Trade Exposure." Review of Economics and Statistics, vol. 92(2), pages 392-407.

Hau, Harald. (2000). "Exchange Rate Determination: The Role of Factor Price Rigidities and Nontradeables". Journal of International Economics, vol. 50(2), pages 421-447.

Hayo, Bernd, and Birgit Uhlenbrock. (2000). "Industry Effects of Monetary Policy in Germany". J. Von Hagen and C. Waller (eds.), "Regional aspects of monetary policy in Europe". Boston: Kluwer, pages 127-158.

Llaudes, Ricardo. (2007). "Monetary Policy Shocks in a Two-Sector Open Economy: An Empirical Study". Working Paper Series 799, European Central Bank.

Lombardo, Giovanni, and Federico Ravenna. (2014). "Openness and Optimal Monetary Policy". Journal of International Economics, vol. 93(1), pages 153-172.

Mihov, Ilian. (2001). "Monetary Policy Implementation and Transmission in the European Monetary Union". Economic Policy, vol. 16(33), pages 369-406.

Newey, Whitney K., and Kenneth D. West. (1987). "A Simple, Positive Semi-definite, Heteroskedasticity and Autocorrelation Consistent Covariance Matrix". Econometrica, vol. 55(3), pages 703-08.

Obstfeld, Maurice, and Kenneth Rogoff. (1995). "Exchange Rate Dynamics Redux". Journal of Political Economy, vol. 103(3), pages 624-60.

Obstfeld, Maurice, and Kenneth Rogoff. (2000). "New Directions for Stochastic Open Economy Models". Journal of International Economics, vol. 50(1), pages 117-153.

Obstfeld, Maurice, and Kenneth Rogoff. (2005). "Global Current Account Imbalances and Exchange Rate Adjustments". Brookings Papers on Economic Activity, Economic Studies Program, The Brookings Institution, vol. 36(1), pages 67-146.

Obstfeld, Maurice, and Kenneth Rogoff (2007). "The Unsustainable U.S. Current Account Position Revisited." NBER Chapters, in: G7 Current Account Imbalances: Sustainability and Adjustment, pages 339-376, National Bureau of Economic Research.

Owyang, Michael T., and Howard J. Wall. (2004). "Structural Breaks and Regional Disparities in the Transmission of Monetary Policy". Working Papers 2003-008, Federal Reserve Bank of St. Louis.

Peersman, Gert, and Frank Smets. (2005). "The Industry Effects of Monetary Policy in the Euro Area". Economic Journal, vol. 115(503), pages 319-342.

Rabanal, Pau, and Vicente Tuesta. (2013). "Nontradable Goods and the Real Exchange 
Rate". Open Economies Review, vol. 24(3), pages 495-535.

Rogerson, Richard. (1988). "Recursive Competitive Equilibrium in Multi-sector Economies." International Economic Review, vol. 29(3), pages 419-30.

Stockman, Alan C., and Linda L. Tesar. (1995). "Tastes and Technology in a Two-Country Model of the Business Cycle: Explaining International Comovements". The American Economic Review, vol. 85(1), pages 168-185. 


\section{Appendices}

\section{A.1 Data used in the estimation of the exogenous processes}

\begin{tabular}{|c|c|c|}
\hline Alias & Description & Source $^{a}$ \\
\hline \multicolumn{3}{|c|}{$\begin{array}{l}\text { Shocks were estimated by fitting AR(1) processes to } \mu, \mu^{*}, \widehat{z}_{T H, t}, \widehat{z}_{T F, t}^{*}, \widehat{z}_{N, t}, \\
\widehat{z}_{N, t}^{*}, \widehat{G} \text { and } \widehat{G}^{*} \text { (hats denote logs). }\end{array}$} \\
\hline$\mu$ & growth rate of money $^{b}$ & OECD MEI \\
\hline$\mu^{*}$ & $\begin{array}{l}\text { arithmetic GDP-weighted average of Canada, France, Germany, } \\
\text { Japan, Mexico and UK money growth rates }\end{array}$ & IMF IFS \\
\hline$\widehat{z}_{T H, t}$ & $=\widehat{Y}_{T H}-\alpha \widehat{n}_{T H}$ & \\
\hline$Y_{T H}$ & Index of production in total manufacturing & OECD MEI \\
\hline$n_{T H}$ & Employees in manufacturing & OECD MEI \\
\hline$\widehat{z}_{T F, t}^{*}$ & $=\widehat{Y}_{T F}^{*}-\alpha \widehat{n}_{T F}^{*}$ & \\
\hline$Y_{T F}^{*}$ & $\begin{array}{l}\text { arithmetic weighted average of index of production in total } \\
\text { manufacturing in Canada, France, Germany, Japan, Mexico and UK } \\
\text { (weights given manufacturing value added in the year 2000, in dollars) }\end{array}$ & OECD MEI \\
\hline$n_{T F}^{*}$ & $\begin{array}{l}\text { sum of manufacturing employees in Canada, France, Germany, Japan, } \\
\text { Mexico and UK }\end{array}$ & $\begin{array}{l}\text { OECD MEI } \\
\text { ONS }\end{array}$ \\
\hline$\widehat{z}_{N, t}$ & $=\widehat{Y}_{N}-\alpha \widehat{n}_{N}$ & \\
\hline$Y_{N}$ & Index of real Gross Domestic Product of services & BEA NIPA \\
\hline$n_{N}$ & $\begin{array}{l}\text { Employees of service-providing industries } \\
\text { (quarterly averages of monthly data) }\end{array}$ & BLS \\
\hline$\widehat{z}_{N, t}^{*}$ & $=\widehat{Y}_{N}^{*}-\alpha \widehat{n}_{N}^{*}$ & \\
\hline$Y_{N}^{*}$ & $\begin{array}{l}\text { sum of service sector GDP of Canada, France, Germany, Japan and UK, } \\
\text { in dollars }\end{array}$ & $\begin{array}{l}\text { OECD QNA } \\
\text { OECD MEI }\end{array}$ \\
\hline$n_{N}^{*}$ & $\begin{array}{l}\text { sum of employees/employed in the service sector } \\
\text { in Canada, France, Germany, Japan and UK }\end{array}$ & $\begin{array}{l}\text { OECD MEI } \\
\text { BLS } \\
\text { Eurostat }\end{array}$ \\
\hline$G$ & Government final consumption expenditure / consumption in the year 2000 & OECD QNA \\
\hline$G^{*}$ & $\begin{array}{l}\text { Geometric GDP-weighted average of France, Germany, Canada, Japan, } \\
\text { Mexico and UK real government final consumption expenditure } \\
\text { (divided by consumption in the year 2000) }\end{array}$ & OECD QNA \\
\hline
\end{tabular}

\footnotetext{
${ }^{a}$ Legend: BEA NIPA = Bureau of Economic Analysis, National Income and Product Accounts;

BLS $=$ Bureau of Labor Statistics; IMF IFS = IMF International Financial Statistics;

OECD MEI = OECD Main Economic Indicators; OECD QNA = OECD Quarterly National Accounts; ONS $=$ Office for National Statistics, UK.

${ }^{b}$ M1 (U.S., France, Germany, Japan), M2 (UK), M1+ (Canada), M1a (Mexico).
} 


\section{A.2 Deriving the equations of Section 4}

This Appendix describes the derivation of the equations presented in Section 4. Variables with a 'hat' denote percentage or log-deviations from the steady state, while the operator ' $d$ ' denotes linear deviations, calculated in proportion to the steady state level of consumption. That is, for any variable $X$, let $X_{0}$ denote the value of the variable at the steady state. Then, $\widehat{X}_{t} \equiv \frac{X_{t}-X_{0}}{X_{0}} \simeq \log \left(\frac{X_{t}}{X_{0}}\right)$, while $d X_{t} \equiv \frac{X_{t}-X_{0}}{C_{0}}$. Money growth rates, government expenditures and bond holdings are all normalised at zero in the steady state.

Profit maximisation implies that the law of one price holds in the steady state: $p_{T H, 0}\left(f_{T H}\right)=$ $e_{0} \cdot p_{T H, 0}^{*}\left(f_{T H}\right)$.

\section{The short-run demand for relative output}

The derivation of the short-run demand for relative output is divided into the following steps:

1. First, find the expressions for the aggregate Home traded and nontraded output demands.

2. Find the log-linearised demands for aggregate Home traded and nontraded output and for Foreign traded output.

3. Using the Home and Foreign aggregate resource constraints, substitute out from the demand for $Y_{T H}$ the share that comes from the Foreign country.

4. Using the formulas for the CES aggregators, substitute out the consumption indexes, then find the short-run demand for relative output.

\section{Step 1}

The domestic demand for output produced by the individual firm $f_{T H}$ is given by:

$$
y_{T H, t}^{H}\left(f_{T H}\right)=\left(\frac{p_{T H, t}\left(f_{T H}\right)}{P_{T H, t}}\right)^{-\eta_{T}} C_{T H, t},
$$

and the export demand is given by:

$$
y_{T H, t}^{F}\left(f_{T H}\right)=\left(\frac{p_{T H, t}^{*}\left(f_{T H}\right)}{P_{T H, t}^{*}}\right)^{-\eta_{T}} C_{T H, t}^{*} .
$$

The aggregate price indexes are: 


$$
\begin{aligned}
& P_{T H, t}=\left(\int_{0}^{1} p_{T H, t}\left(f_{T H}\right)^{1-\eta_{T}} d f_{T H}\right)^{\frac{1}{1-\eta_{T}}}, \\
& P_{T H, t}^{*}=\left(\int_{0}^{1} p_{T H, t}^{*}\left(f_{T H}\right)^{1-\eta_{T}} d f_{T H}\right)^{\frac{1}{1-\eta_{T}}} .
\end{aligned}
$$

Using the following definitions:

$$
\begin{aligned}
Y_{T H, t}^{H} & \equiv\left[\int_{0}^{1} y_{T H, t}^{H}\left(f_{T H}\right)^{\frac{\eta_{T}-1}{\eta_{T}}} d f_{T H}\right]^{\frac{\eta_{T}}{\eta_{T}-1}}, \\
Y_{T H, t}^{F} & \equiv\left[\int_{0}^{1} y_{T H, t}^{F}\left(f_{T H}\right)^{\frac{\eta_{T}-1}{\eta_{T}}} d f_{T H}\right]^{\frac{\eta_{T}}{\eta_{T}-1}},
\end{aligned}
$$

we obtain:

$$
Y_{T H, t}^{H}=C_{T H, t}, \quad Y_{T H, t}^{F}=C_{T H, t}^{*} .
$$

Moreover:

$$
Y_{T H, t} \equiv Y_{T H, t}^{H}+Y_{T H, t}^{F}=C_{T H, t}+C_{T H, t}^{*},
$$

thus log-linearising (23):

$$
\widehat{Y}_{T H, t}=k_{1} \widehat{Y}_{T H, t}^{H}+\left(1-k_{1}\right) \widehat{Y}_{T H, t}^{F}
$$

where $k_{1}=\frac{C_{T H 0}}{Y_{T H 0}}=(1-\delta)\left(\frac{P_{T H 0}}{P_{T 0}}\right)^{1-\theta}$. The demand for aggregate Home nontraded output is similarly obtained, and it includes government expenditure:

$$
Y_{N, t}=C_{N, t}+G_{t}
$$

\section{Step 2}

The price indexes in the traded sector are defined as arithmetic weighted averages, with weights taken from the steady state: 


$$
\begin{gathered}
P_{T H, t}^{y} \equiv \frac{P_{T H, t} \cdot Y_{T H 0}^{H}+e_{t} P_{T H, t}^{*} \cdot Y_{T H 0}^{F}}{P_{T H 0} \cdot Y_{T H 0}^{H}+e_{0} P_{T H 0}^{*} \cdot Y_{T H 0}^{F}}, \\
P_{T F, t}^{y^{*}} \equiv \frac{\frac{P_{T F, t}}{e_{t}} \cdot Y_{T F 0}^{H}+P_{T F, t}^{*} \cdot Y_{T F 0}^{F}}{\frac{P_{T F 0}}{e_{0}} \cdot Y_{T F 0}^{H}+P_{T F 0}^{*} \cdot Y_{T F 0}^{F}}
\end{gathered}
$$

Log-linearising:

$$
\begin{aligned}
\widehat{P}_{T H, t}^{y} & =k_{1} \widehat{P}_{T H, t}+\left(1-k_{1}\right)\left(\widehat{e}_{t}+\widehat{P}_{T H, t}^{*}\right), \\
\widehat{P}_{T F, t}^{y^{*}} & =k_{1}^{*}\left(\widehat{P}_{T F, t}-\widehat{e}_{t}\right)+\left(1-k_{1}^{*}\right) \widehat{P}_{T F, t}^{*} .
\end{aligned}
$$

Substituting into the total demand for aggregate Home traded output (23) the following expressions:

$$
\begin{gathered}
C_{T H, t}=(1-\delta)\left(\frac{P_{T H, t}}{P_{T, t}}\right)^{-\theta} C_{T, t}, \\
C_{T H, t}^{*}=\left(1-\delta^{*}\right)\left(\frac{P_{T H, t}^{*}}{P_{T, t}^{*}}\right)^{-\theta} C_{T, t}^{*}, \\
\left(\frac{P_{T H, t}}{P_{T, t}}\right)^{-\theta}=\left[(1-\delta)+\delta\left(\frac{P_{T F, t}}{P_{T H, t}}\right)^{1-\theta}\right]^{\frac{\theta}{1-\theta}}, \\
\left(\frac{P_{T H, t}^{*}}{P_{T, t}^{*}}\right)^{-\theta}=\left[\left(1-\delta^{*}\right)+\delta^{*}\left(\frac{P_{T H, t}^{*}}{P_{T F, t}^{*}}\right)^{\theta-1}\right]^{\frac{\theta}{1-\theta}},
\end{gathered}
$$

and log-linearising, we get:

$$
\begin{gathered}
\widehat{Y}_{T H, t}=k_{1} \widehat{C}_{T, t}+\left(1-k_{1}\right) \widehat{C}_{T, t}^{*} \\
+\theta\left(1-k_{1}\right)\left[k_{1}\left(\widehat{P}_{T F, t}-\widehat{P}_{T H, t}\right)+\left(1-k_{1}^{*}\right)\left(\widehat{P}_{T F, t}^{*}-\widehat{P}_{T H, t}^{*}\right)\right],
\end{gathered}
$$

where the coefficient $k_{1}^{*}=\frac{C_{T F 0}}{Y_{T F, t}^{*}}=\left(1-\delta^{*}\right)\left(\frac{P_{T H 0}^{*}}{P_{T 0}^{*}}\right)^{1-\theta}$ can be computed from the steady state equations. Using the same procedure for Home nontraded output and Foreign traded output we get: 


$$
\widehat{Y}_{N, t}=\widehat{C}_{N, t}+k_{7} d G_{t}
$$

$$
\widehat{Y}_{T F, t}^{*}=k_{1}^{*} \widehat{C}_{T, t}+\left(1-k_{1}^{*}\right) \widehat{C}_{T, t}^{*}-\theta k_{1}^{*}\left[k_{1}\left(\widehat{P}_{T F, t}-\widehat{P}_{T H, t}\right)+\left(1-k_{1}^{*}\right)\left(\widehat{P}_{T F, t}^{*}-\widehat{P}_{T H, t}^{*}\right)\right],
$$

where $k_{7}=\frac{C_{0}}{C_{N, 0}}$ is a coefficient from the steady state.

\section{Step 3}

Equations (28) and (30) together imply:

$$
\begin{gathered}
\widehat{Y}_{T H, t}-\widehat{Y}_{T F, t}^{*}=\left(k_{1}-k_{1}^{*}\right)\left(\widehat{C}_{T, t}-\widehat{C}_{T, t}^{*}\right) \\
+\theta\left(1-k_{1}+k_{1}^{*}\right)\left[k_{1}\left(\widehat{P}_{T F, t}-\widehat{P}_{T H, t}\right)+\left(1-k_{1}^{*}\right)\left(\widehat{P}_{T F, t}^{*}-\widehat{P}_{T H, t}^{*}\right)\right] .
\end{gathered}
$$

Equation (31) is the log-linearised demand for $\frac{Y_{T H}}{Y_{T F}^{*}}$ obtained from the individual demand equations.

The Home and Foreign aggregate resource constraints are:

$$
\begin{aligned}
& B_{t} P_{T, t}=\left(1+r_{t-1}\right) B_{t-1} P_{T, t}+P_{T H, t} \cdot Y_{T H, t}^{H}+e_{t} P_{T H, t}^{*} \cdot Y_{T H, t}^{F}-P_{T, t} C_{T, t}, \\
& B_{t}^{*} \frac{P_{T, t}}{e_{t}}=\left(1+r_{t-1}\right) B_{t-1}^{*} \frac{P_{T, t}}{e_{t}}+P_{T F, t}^{*} \cdot Y_{T F, t}^{F}+\frac{P_{T F, t}}{e_{t}} \cdot Y_{T F, t}^{H}-P_{T, t}^{*} \cdot C_{T, t}^{*} .
\end{aligned}
$$

After log-linearising around a steady state with $B_{0}=0$ and government expenditures equal to zero, and substituting prices out, we obtain:

$$
\begin{gathered}
d B_{t}=\frac{1}{\beta} d B_{t-1}-\left(1-k_{1}\right) k_{2} k_{3}\left(\widehat{P}_{T F, t}-\widehat{P}_{T H, t}^{*}-\widehat{e}_{t}\right)+k_{2} k_{3} \widehat{Y}_{T H, t}-k_{2} k_{3} \widehat{C}_{T, t}, \\
\frac{P_{T 0}}{e_{0} P_{T 0}^{*}} d B_{t}^{*}=\frac{P_{T 0}}{e_{0} P_{T 0}^{*}} \frac{1}{\beta} d B_{t-1}^{*}+k_{1}^{*} k_{2}^{*} k_{3}^{*}\left(\widehat{P}_{T F, t}-\widehat{P}_{T H, t}^{*}-\widehat{e}_{t}\right)+k_{2}^{*} k_{3}^{*} \widehat{Y}_{T F, t}^{F}-k_{2}^{*} k_{3}^{*} \widehat{C}_{T, t}^{*},
\end{gathered}
$$


where $k_{2}=\frac{P_{T H 0} Y_{T H 0}}{P_{0} C_{0}}=\frac{P_{T 0} C_{T 0}}{P_{0} C_{0}}=(1-\gamma)\left(\frac{P_{T 0}}{P_{0}}\right)^{1-\phi}, k_{2}^{*}=\frac{P_{T F 0}^{*} Y_{T F 0}^{*}}{P_{0}^{*} C_{0}^{* *}}=\frac{P_{T 0}^{*} C_{T 0}^{*}}{P_{0}^{* *} C_{0}^{* *}}=(1-\gamma)\left(\frac{P_{T 0}^{*}}{P_{0}^{*}}\right)^{1-\phi}$, $k_{3}=\frac{P_{0}}{P_{T 0}}$ and $k_{3}^{*}=\frac{P_{0}^{*}}{P_{T 0}^{*}}$ are coefficients from the steady state. Since $d B_{t}^{*}=-\frac{C_{0}}{C_{0}^{*}} d B_{t}$, we obtain:

$$
\begin{gathered}
\widehat{Y}_{T H, t}=\frac{1}{k_{2} k_{3}}\left(d B_{t}-\frac{1}{\beta} d B_{t-1}\right)+\left(1-k_{1}\right)\left(\widehat{P}_{T F, t}-\widehat{P}_{T H, t}^{*}-\widehat{e}_{t}\right)+\widehat{C}_{T, t}, \\
\widehat{Y}_{T F, t}^{*}=-\frac{1}{k_{2}^{*} k_{3}^{*}} \frac{P_{T 0}}{e_{0} P_{T 0}^{*}} \frac{C_{0}}{C_{0}^{*}}\left(d B_{t}-\frac{1}{\beta} d B_{t-1}\right)-k_{1}^{*}\left(\widehat{P}_{T F, t}-\widehat{P}_{T H, t}^{*}-\widehat{e}_{t}\right)+\widehat{C}_{T, t}^{*} .
\end{gathered}
$$

Therefore:

$$
\begin{aligned}
\widehat{Y}_{T H, t}-\widehat{Y}_{T F, t}^{*} & =\left(1-k_{1}+k_{1}^{*}\right) k_{4}\left(d B_{t}-\frac{1}{\beta} d B_{t-1}\right)+\widehat{C}_{T, t}-\widehat{C}_{T, t}^{*} \\
+ & \left(1-k_{1}+k_{1}^{*}\right)\left(\widehat{P}_{T F, t}-\widehat{P}_{T H, t}^{*}-\widehat{e}_{t}\right)
\end{aligned}
$$

where $k_{4}=\frac{1}{1-k_{1}+k_{1}^{*}}\left(\frac{1}{k_{2} k_{3}}+\frac{1}{k_{2}^{*} k_{3}^{*}} \frac{P_{T 0}}{e_{0} P_{T 0}^{*}} \frac{C_{0}}{C_{0}^{*}}\right)$. Equation (32) is the log-linearised demand for $\frac{Y_{T H, t}}{Y_{T F, t}^{*}}$ obtained from the Home and Foreign aggregate resource constraints. Equations (31) and (32) together imply:

$$
\begin{gathered}
\widehat{C}_{T, t}^{*}=\widehat{C}_{T, t}+k_{4}\left(d B_{t}-\frac{1}{\beta} d B_{t-1}\right)+\left(\widehat{P}_{T F, t}-\widehat{P}_{T H, t}^{*}-\widehat{e}_{t}\right) \\
-\theta\left[k_{1}\left(\widehat{P}_{T F, t}-\widehat{P}_{T H, t}\right)+\left(1-k_{1}^{*}\right)\left(\widehat{P}_{T F, t}^{*}-\widehat{P}_{T H, t}^{*}\right)\right] .
\end{gathered}
$$

Substituting (33) into (28) we obtain:

$$
\widehat{Y}_{T H, t}=\widehat{C}_{T, t}+\left(1-k_{1}\right)\left(\widehat{P}_{T F, t}-\widehat{P}_{T H, t}^{*}-\widehat{e}_{t}\right)+\left(1-k_{1}\right) k_{4}\left(d B_{t}-\frac{1}{\beta} d B_{t-1}\right)
$$

\section{Step 4}

From the equations:

$$
C_{T, t}=(1-\gamma)\left(\frac{P_{T, t}}{P_{t}}\right)^{-\phi} C_{t}
$$




$$
C_{N, t}=\gamma\left(\frac{P_{N, t}}{P_{t}}\right)^{-\phi} C_{t}
$$

and substituting out the price indexes, we get the log-linearised demands for $C_{T}$ and $C_{N}$ :

$$
\begin{gathered}
\widehat{C}_{T, t}=-\phi\left(1-k_{2}\right)\left[k_{1} \widehat{P}_{T H, t}+\left(1-k_{1}\right) \widehat{P}_{T F, t}-\widehat{P}_{N, t}\right]+\widehat{C}_{t} \\
\widehat{C}_{N, t}=\phi k_{2}\left[k_{1} \widehat{P}_{T H, t}+\left(1-k_{1}\right) \widehat{P}_{T F, t}-\widehat{P}_{N, t}\right]+\widehat{C}_{t} .
\end{gathered}
$$

By substituting (35) into (34) we obtain:

$$
\begin{aligned}
\widehat{Y}_{T H, t}= & -\phi\left(1-k_{2}\right)\left[k_{1} \widehat{P}_{T H, t}+\left(1-k_{1}\right) \widehat{P}_{T F, t}-\widehat{P}_{N, t}\right] \\
& +\left(1-k_{1}\right)\left(\widehat{P}_{T F, t}-\widehat{P}_{T H, t}^{*}-\widehat{e}_{t}\right)+\widehat{C}_{t}+\left(1-k_{1}\right) k_{4}\left(d B_{t}-\frac{1}{\beta} d B_{t-1}\right) .
\end{aligned}
$$

And by substituting (36) into (29) we obtain:

$$
\widehat{Y}_{N, t}=\phi k_{2}\left[k_{1} \widehat{P}_{T H, t}+\left(1-k_{1}\right) \widehat{P}_{T F, t}-\widehat{P}_{N, t}\right]+\widehat{C}_{t}+k_{7} d G_{t}
$$

Finally, by subtracting (38) from (37) and after some substitutions we obtain the short-run demand for relative output:

$$
\widehat{Y}_{T H, t}-\widehat{Y}_{N, t}=-\phi\left(\widehat{P}_{T H, t}^{y}-\widehat{P}_{N, t}\right)+(1-\phi)\left(1-k_{1}\right) \widehat{T}_{t}+\left(1-k_{1}\right) k_{4}\left(d B_{t}-\frac{1}{\beta} d B_{t-1}\right)-k_{7} d G_{t}
$$

Under the assumption that in period $t-1$ the economy is at its steady state, $d B_{t-1}=0$. Notice that, in the special case $\theta=1, k_{1}=1-\delta$, so the demand is:

$$
\widehat{Y}_{T H, t}-\widehat{Y}_{N, t}=-\phi\left(\widehat{P}_{T H, t}^{y}-\widehat{P}_{N, t}\right)+\delta(1-\phi) \widehat{T}_{t}+\delta k_{4} d B_{t}-k_{7} d G_{t}
$$

\section{The short-run supply for relative output}

The maximisation problem faced by firm $f_{T H}$ in the Home traded sector changing prices at time $t$ is: 


$$
\begin{array}{ll}
\max \quad E_{t} \sum_{j=0}^{\infty}\left(\varphi_{T H} \beta\right)^{j} Q_{t, t+j}\left[\begin{array}{c}
\frac{p_{T H, t}\left(f_{T H}\right)}{P_{t+j}} \cdot y_{T H, t+j \mid t}^{H}\left(f_{T H}\right) \\
+e_{t+j} \frac{p_{T H, t+j}^{*}\left(f_{T H}\right)}{P_{t+j}} y_{T H, t+j \mid t}^{F}\left(f_{T H}\right) \\
-\frac{W_{T H, t+j}}{P_{t+j}} \cdot \widetilde{h}_{T H, t+j \mid t}\left(f_{T H}\right)
\end{array}\right], \\
\text { s.t. } \quad y_{T H, t+j \mid t}^{H}\left(f_{T H}\right)=\left(\frac{p_{T H, t}\left(f_{T H}\right)}{P_{T H, t+j}}\right)^{-\eta_{T}} C_{T H, t+j}, \\
y_{T H, t+j \mid t}^{F}\left(f_{T H}\right) & =\left(\frac{p_{T H, t+j \mid t}^{*}\left(f_{T H}\right)}{P_{T H, t+j}^{*}}\right)^{-\eta_{T}} C_{T H, t+j}^{*}, \\
p_{T H, t+j \mid t}^{*}\left(f_{T H}\right) & =\widetilde{p}_{T H, t}\left(f_{T H}\right) e_{t+j}^{-\zeta} .
\end{array}
$$

The first-order conditions describing optimal price setting are as follows:

$$
\begin{aligned}
& E_{t} \sum_{j=0}^{\infty}\left(\varphi_{T H} \beta\right)^{j} Q_{t, t+j}\left[\begin{array}{c}
\frac{1}{P_{t+j}} \cdot y_{T H, t+j \mid t}^{H}\left(f_{T H}\right)\left(1-\eta_{T}\right) \\
+\eta_{T} \cdot \frac{W_{T H, t+j}}{P_{t+j}} \cdot \frac{\vartheta \widetilde{h}_{T H, t+j \mid t}\left(f_{T H}\right)}{\vartheta y_{T H, t+j \mid t}^{H}\left(f_{T H}\right)} \cdot \frac{y_{T H, t+j \mid t}^{H}\left(f_{T H}\right)}{p_{T H, t}\left(f_{T H}\right)}
\end{array}\right]=0, \\
& E_{t} \sum_{j=0}^{\infty}\left(\varphi_{T H} \beta\right)^{j} Q_{t, t+j}\left[\begin{array}{c}
\frac{e_{t+j}^{1-\zeta}}{P_{t+j}} \cdot y_{T H, t+j \mid t}^{F}\left(f_{T H}\right)\left(1-\eta_{T}\right) \\
+\eta_{T} \cdot \frac{W_{T H, t+j}}{P_{t+j}} \cdot \frac{\vartheta \widetilde{h}_{T H, t+j \mid t}\left(f_{T H}\right)}{\vartheta y_{T H, t+j \mid t}^{F}\left(f_{T H}\right)} \cdot \frac{y_{T H, t+j \mid t}^{F}\left(f_{T H}\right)}{\widetilde{p}_{T H, t}\left(f_{T H}\right)}
\end{array}\right]=0 .
\end{aligned}
$$

Given the sequences $\left\{C_{t}\right\},\left\{P_{t}\right\},\left\{e_{t}\right\},\left\{W_{T H, t}\right\},\left\{P_{T H, t}\right\},\left\{P_{T H, t}^{*}\right\},\left\{C_{T H, t}\right\}$ and $\left\{C_{T H, t}^{*}\right\}$, the sequences of shocks and the initial conditions, each producer that chooses new prices in period $t$ will choose the same $p_{T H, t}\left(f_{T H}\right)$ and $\widetilde{p}_{T H, t}\left(f_{T H}\right)$, and the same output levels $y_{T H, t+j \mid t}^{H}\left(f_{T H}\right)$ and $y_{T H, t+j \mid t}^{F}\left(f_{T H}\right)$. Then the optimal prices $\left\{p_{T H, t}\left(f_{T H}\right), P_{T H, t}\right\}\left\{\widetilde{p}_{T H, t}\left(f_{T H}\right), \widetilde{P}_{T H, t}\right\}$ must satisfy the first-order conditions above and the following laws of motion:

$$
\begin{aligned}
& P_{T H, t}=\left[\varphi_{T H} P_{T H, t-1}^{1-\eta_{T}}+\left(1-\varphi_{T H}\right) p_{T H, t}\left(f_{T H}\right)^{1-\eta_{T}}\right]^{\frac{1}{1-\eta_{T}}}, \\
& \widetilde{P}_{T H, t}=\left[\varphi_{T H} \widetilde{P}_{T H, t-1}^{1-\eta_{T}}+\left(1-\varphi_{T H}\right) \widetilde{p}_{T H, t}\left(f_{T H}\right)^{1-\eta_{T}}\right]^{\frac{1}{1-\eta_{T}}} .
\end{aligned}
$$

By log-linearising the laws of motion above we get:

$$
\begin{aligned}
& \widehat{X}_{t}=\frac{\varphi_{T H}}{1-\varphi_{T H}} \pi_{T H, t}, \\
& \widehat{\widetilde{X}}_{t}=\frac{\varphi_{T H}}{1-\varphi_{T H}} \widetilde{\pi}_{T H, t},
\end{aligned}
$$


where $X_{t} \equiv \frac{p_{T H, t}\left(f_{T H}\right)}{P_{T H, t}}, \widetilde{X}_{t} \equiv \frac{\widetilde{p}_{T H, t}\left(f_{T H}\right)}{\widetilde{P}_{T H, t}}, \pi_{T H, t} \equiv \log \frac{P_{T H, t}}{P_{T H, t-1}}$, and $\widetilde{\pi}_{T H, t} \equiv \log \frac{\widetilde{P}_{T H, t}}{\widetilde{P}_{T H, t-1}}$. Notice that:

$$
\begin{aligned}
& \widehat{X}_{t+j}=\widehat{X}_{t}-\sum_{s=1}^{j} \pi_{T H, t+s}=\frac{\varphi_{T H}}{1-\varphi_{T H}} \pi_{T H, t}-\sum_{s=1}^{j} \pi_{T H, t+s}, \\
& \widehat{\widetilde{X}}_{t+j}=\widehat{\widetilde{X}}_{t}-\sum_{s=1}^{j} \widetilde{\pi}_{T H, t+s}=\frac{\varphi_{T H}}{1-\varphi_{T H}} \widetilde{\pi}_{T H, t}-\sum_{s=1}^{j} \tilde{\pi}_{T H, t+s},
\end{aligned}
$$

where $X_{t+j} \equiv \frac{p_{T H, t}\left(f_{T H}\right)}{P_{T H, t+j}}$ and $\widetilde{X}_{t+j} \equiv \frac{\widetilde{p}_{T H, t}\left(f_{T H}\right)}{\widetilde{P}_{T H, t+j}}$. From the individual firm's production function:

$$
y_{T H, t}^{H}\left(f_{T H}\right)+y_{T H, t}^{F}\left(f_{T H}\right)=z_{T H, t} \cdot \widetilde{h}_{T H, t}\left(f_{T H}\right)^{\alpha_{T}}
$$

we compute the derivatives in the following way:

$\frac{\vartheta \widetilde{h}_{T H, t+j \mid t}\left(f_{T H}\right)}{\vartheta y_{T H, t+j \mid t}^{H}\left(f_{T H}\right)}=\frac{\vartheta \widetilde{h}_{T H, t+j \mid t}\left(f_{T H}\right)}{\vartheta y_{T H, t+j \mid t}^{F}\left(f_{T H}\right)}=\frac{1}{\alpha_{T}} \cdot\left(z_{T H, t+j}\right)^{-\frac{1}{\alpha_{T}}} \cdot\left(y_{T H, t+j \mid t}^{H}\left(f_{T H}\right)+y_{T H, t+j \mid t}^{F}\left(f_{T H}\right)\right)^{\frac{1}{\alpha_{T}}-1}$.

Substituting the above expression into the first-order condition (39) and multiplying by $p_{T H, t}\left(f_{T H}\right)$ we obtain:

$$
E_{t} \sum_{j=0}^{\infty}\left(\varphi_{T H}^{\beta}\right)^{j} Q_{t, t+j}\left[\begin{array}{c}
\frac{p_{T H, t}\left(f_{T H}\right)}{P_{T H, t+j}} \frac{P_{T H, t+j}}{P_{t+j}} \cdot y_{T H, t+j \mid t}^{H}\left(f_{T H}\right)\left(1-\eta_{T}\right) \\
+\frac{\eta_{T}}{\alpha_{T}} \cdot\left(z_{T H, t+j}\right)^{-\frac{1}{\alpha_{T}}} \cdot \frac{W_{T H, t+j}}{P_{t+j}} \cdot \\
\cdot\left(y_{T H, t+j \mid t}^{H}\left(f_{T H}\right)+y_{T H, t+j \mid t}^{F}\left(f_{T H}\right)\right)^{\frac{1}{\alpha_{T}}-1} \cdot y_{T H, t+j \mid t}^{H}\left(f_{T H}\right)
\end{array}\right]=0
$$

analogously:

$$
E_{t} \sum_{j=0}^{\infty}\left(\varphi_{T H} \beta\right)^{j} Q_{t, t+j}\left[\begin{array}{c}
e_{t+j}^{1-\zeta} \frac{\widetilde{p}_{T H, t}\left(f_{T H}\right)}{\widetilde{P}_{T H, t+j}} \frac{\widetilde{P}_{T H, t+j}}{P_{t+j}} \cdot y_{T H, t+j \mid t}^{F}\left(f_{T H}\right)\left(1-\eta_{T}\right) \\
+\frac{\eta_{T}}{\alpha_{T}} \cdot\left(z_{T H, t+j}\right)^{-\frac{1}{\alpha_{T}}} \cdot \frac{W_{T H, t+j}}{P_{t+j}} \cdot \\
\cdot\left(y_{T H, t+j \mid t}^{H}\left(f_{T H}\right)+y_{T H, t+j \mid t}^{F}\left(f_{T H}\right)\right)^{\frac{1}{\alpha_{T}}-1} \cdot y_{T H, t+j \mid t}^{F}\left(f_{T H}\right)
\end{array}\right]=0 .
$$

Notice that the two first-order conditions imply that the law of one price is recovered in the steady state, as stated earlier.

Now we log-linearise around a deterministic equilibrium or steady state in which all the 
exogenous stochastic processes are set equal to their unconditional means, their variances are set to zero, and individuals hold no internationally traded bond. In this deterministic equilibrium $p_{T H, 0}\left(f_{T H}\right)=P_{T H, 0}$ and $\widetilde{p}_{T H, 0}\left(f_{T H}\right)=\widetilde{P}_{T H, 0}$. We obtain:

$$
\begin{gathered}
E_{t} \sum_{j=0}^{\infty}\left(\varphi_{T H} \beta\right)^{j}\left[\begin{array}{c}
\widehat{X}_{t+j}+\widehat{P}_{T H, t+j}+\frac{1}{\alpha_{T}} \cdot \widehat{z}_{T H, t+j}-\widehat{W}_{T H, t+j} \\
-\frac{1-\alpha_{T}}{\alpha_{T}} k_{1} \widehat{y}_{T H, t+j \mid t}^{H}\left(f_{T H}\right)-\frac{1-\alpha_{T}}{\alpha_{T}}\left(1-k_{1}\right) \widehat{y}_{T H, t+j \mid t}^{F}\left(f_{T H}\right)
\end{array}\right]=0, \\
E_{t} \sum_{j=0}^{\infty}\left(\varphi_{T H} \beta\right)^{j}\left[\begin{array}{c}
(1-\zeta) \widehat{e}_{t+j}+\widehat{\widetilde{X}}_{t+j}+\widehat{\widetilde{P}}_{T H, t+j}+\frac{1}{\alpha_{T}} \cdot \widehat{z}_{T H, t+j}-\widehat{W}_{T H, t+j} \\
-\frac{1-\alpha_{T}}{\alpha_{T}} k_{1} \widehat{y}_{T H, t+j \mid t}^{H}\left(f_{T H}\right)-\frac{1-\alpha_{T}}{\alpha_{T}}\left(1-k_{1}\right) \widehat{y}_{T H, t+j \mid t}^{F}\left(f_{T H}\right)
\end{array}\right]=0,
\end{gathered}
$$

where $k_{1} \equiv \frac{C_{T H, 0}}{C_{T H, 0}+C_{T H, 0}^{*}}=\frac{Y_{T H, 0}^{H}}{Y_{T H, 0}^{H}+Y_{T H, 0}^{F}}$.

By log-linearising the demands for output:

$$
\begin{aligned}
& \widehat{y}_{T H, t+j \mid t}^{H}\left(f_{T H}\right)=-\eta_{T} \cdot \widehat{X}_{t+j}+\widehat{Y}_{T H, t+j}^{H}, \\
& \widehat{y}_{T H, t+j \mid t}^{F}\left(f_{T H}\right)=-\eta_{T} \cdot \widehat{\widetilde{X}}_{t+j}+\widehat{Y}_{T H, t+j}^{F},
\end{aligned}
$$

since $\frac{\widetilde{p}_{T H, t}\left(f_{T H}\right)}{\widetilde{P}_{T H, t+j}}=\frac{p_{T H, t+j \mid t}^{*}\left(f_{T H}\right)}{P_{T H, t+j}^{*}}$.

We can substitute into the log-linearised first-order conditions the expressions for $\widehat{X}_{t+j}$, $\widehat{\widetilde{X}}_{t+j}$ and $\widehat{y}_{T H, t+j \mid t}^{H}\left(f_{T H}\right), \widehat{y}_{T H, t+j \mid t}^{F}\left(f_{T H}\right)$, and after some simplifications we obtain:

$$
E_{t} \sum_{j=0}^{\infty}\left(\varphi_{T H} \beta\right)^{j}\left[\begin{array}{c}
\left(1+\eta_{T} \frac{1-\alpha_{T}}{\alpha_{T}} k_{1}\right) \cdot\left(\frac{\varphi_{T H}}{1-\varphi_{T H}} \pi_{T H, t}-\sum_{s=1}^{j} \pi_{T H, t+s}\right) \\
+\eta_{T} \frac{1-\alpha_{T}}{\alpha_{T}}\left(1-k_{1}\right) \cdot\left(\frac{\varphi_{T H}}{1-\varphi_{T H}} \widetilde{\pi}_{T H, t}-\sum_{s=1}^{j} \widetilde{\pi}_{T H, t+s}\right) \\
+\widehat{P}_{T H, t+j}-\widehat{W}_{T H, t+j}+\frac{1}{\alpha_{T}} \cdot \widehat{z}_{T H, t+j} \\
-\frac{1-\alpha_{T}}{\alpha_{T}} k_{1} \widehat{Y}_{T H, t+j}^{H}-\frac{1-\alpha_{T}}{\alpha_{T}}\left(1-k_{1}\right) \widehat{Y}_{T H, t+j}^{F}
\end{array}\right]=0
$$




$$
E_{t} \sum_{j=0}^{\infty}\left(\varphi_{T H} \beta\right)^{j}\left[\begin{array}{c}
\eta_{T} \frac{1-\alpha_{T}}{\alpha_{T}} k_{1} \cdot\left(\frac{\varphi_{T H}}{1-\varphi_{T H}} \pi_{T H, t}-\sum_{s=1}^{j} \pi_{T H, t+s}\right) \\
+\left(1+\eta_{T} \frac{1-\alpha_{T}}{\alpha_{T}}\left(1-k_{1}\right)\right) \cdot\left(\frac{\varphi_{T H}}{1-\varphi_{T H}} \widetilde{\pi}_{T H, t}-\sum_{s=1}^{j} \widetilde{\pi}_{T H, t+s}\right) \\
+(1-\zeta) \widehat{e}_{t+j}+\widehat{\widetilde{P}}_{T H, t+j}-\widehat{W}_{T H, t+j}+\frac{1}{\alpha_{T}} \cdot \widehat{z}_{T H, t+j} \\
-\frac{1-\alpha_{T}}{\alpha_{T}} k_{1} \widehat{Y}_{T H, t+j}^{H}-\frac{1-\alpha_{T}}{\alpha_{T}}\left(1-k_{1}\right) \widehat{Y}_{T H, t+j}^{F}
\end{array}\right]=0
$$

which can be further simplified as follows:

$$
\begin{aligned}
& \frac{1}{1-\varphi_{T H} \beta}\left(1+\eta_{T} \frac{1-\alpha_{T}}{\alpha_{T}} k_{1}\right) \frac{\varphi_{T H}}{1-\varphi_{T H}} \pi_{T H, t}+\frac{1}{1-\varphi_{T H} \beta} \eta_{T} \frac{1-\alpha_{T}}{\alpha_{T}}\left(1-k_{1}\right) \frac{\varphi_{T H}}{1-\varphi_{T H}} \widetilde{\pi}_{T H, t} \\
& =\frac{1}{1-\varphi_{T H} \beta}\left(1+\eta_{T} \frac{1-\alpha_{T}}{\alpha_{T}} k_{1}\right) E_{t} \sum_{j=1}^{\infty}\left(\varphi_{T H} \beta\right)^{j} \pi_{T H, t+j} \\
& +\frac{1}{1-\varphi_{T H} \beta} \eta_{T} \frac{1-\alpha_{T}}{\alpha_{T}}\left(1-k_{1}\right) E_{t} \sum_{j=1}^{\infty}\left(\varphi_{T H} \beta\right)^{j} \widetilde{\pi}_{T H, t+j} \\
& -E_{t} \sum_{j=0}^{\infty}\left(\varphi_{T H} \beta\right)^{j}\left[\begin{array}{c}
+\widehat{P}_{T H, t+j}-\widehat{W}_{T H, t+j}+\frac{1}{\alpha_{T}} \cdot \widehat{z}_{T H, t+j} \\
-\frac{1-\alpha_{T}}{\alpha_{T}} k_{1} \widehat{Y}_{T H, t+j}^{H}-\frac{1-\alpha_{T}}{\alpha_{T}}\left(1-k_{1}\right) \widehat{Y}_{T H, t+j}^{F}
\end{array}\right], \\
& \frac{1}{1-\varphi_{T H} \beta} \eta_{T} \frac{1-\alpha_{T}}{\alpha_{T}} k_{1} \frac{\varphi_{T H}}{1-\varphi_{T H}} \pi_{T H, t}+\frac{1}{1-\varphi_{T H}^{\beta}}\left(1+\eta_{T} \frac{1-\alpha_{T}}{\alpha_{T}}\left(1-k_{1}\right)\right) \frac{\varphi_{T H}}{1-\varphi_{T H}} \widetilde{\pi}_{T H, t}, \\
& =\frac{1}{1-\varphi_{T H} \beta} \eta_{T} \frac{1-\alpha_{T}}{\alpha_{T}} k_{1} E_{t} \sum_{j=1}^{\infty}\left(\varphi_{T H} \beta\right)^{j} \pi_{T H, t+j} \\
& +\frac{1}{1-\varphi_{T H} \beta}\left(1+\eta_{T} \frac{1-\alpha_{T}}{\alpha_{T}}\left(1-k_{1}\right)\right) E_{t} \sum_{j=1}^{\infty}\left(\varphi_{T H} \beta\right)^{j} \widetilde{\pi}_{T H, t+j} \\
& -E_{t} \sum_{j=0}^{\infty}\left(\varphi_{T H} \beta\right)^{j}\left[\begin{array}{c}
+(1-\zeta) \widehat{e}_{t+j}+\widehat{\widetilde{P}}_{T H, t+j}-\widehat{W}_{T H, t+j}+\frac{1}{\alpha_{T}} \cdot \widehat{z}_{T H, t+j} \\
-\frac{1-\alpha_{T}}{\alpha_{T}} k_{1} \widehat{Y}_{T H, t+j}^{H}-\frac{1-\alpha_{T}}{\alpha_{T}}\left(1-k_{1}\right) \widehat{Y}_{T H, t+j}^{F}
\end{array}\right] .
\end{aligned}
$$

Finally, simplifying and using the law of iterated expectations, we can write:

$$
\begin{aligned}
&\left(1+\eta_{T} \frac{1-\alpha_{T}}{\alpha_{T}} k_{1}\right) \pi_{T H, t}+\eta_{T} \frac{1-\alpha_{T}}{\alpha_{T}}\left(1-k_{1}\right) \widetilde{\pi}_{T H, t} \\
&=\left(1+\eta_{T} \frac{1-\alpha_{T}}{\alpha_{T}} k_{1}\right) \beta E_{t} \pi_{T H, t+1}+\eta_{T} \frac{1-\alpha_{T}}{\alpha_{T}}\left(1-k_{1}\right) \beta E_{t} \widetilde{\pi}_{T H, t+1} \\
&+\left(1-\varphi_{T H} \beta\right) \frac{1-\varphi_{T H}}{\varphi_{T H}}\left[\begin{array}{c}
\widehat{W}_{T H, t}-\widehat{P}_{T H, t}-\frac{1}{\alpha_{T}} \cdot \widehat{z}_{T H, t} \\
+\frac{1-\alpha_{T}}{\alpha_{T}} k_{1} \widehat{Y}_{T H, t}^{H}+\frac{1-\alpha_{T}}{\alpha_{T}}\left(1-k_{1}\right) \widehat{Y}_{T H, t}^{F}
\end{array}\right], \\
& \eta_{T} \frac{1-\alpha_{T}}{\alpha_{T}} k_{1} \pi_{T H, t}+\left(1+\eta_{T} \frac{1-\alpha_{T}}{\alpha_{T}}\left(1-k_{1}\right)\right) \widetilde{\pi}_{T H, t} \\
&=\eta_{T} \frac{1-\alpha_{T}}{\alpha_{T}} k_{1} \beta E_{t} \pi_{T H, t+1}+\left(1+\eta_{T} \frac{1-\alpha_{T}}{\alpha_{T}}\left(1-k_{1}\right)\right) \beta E_{t} \widetilde{\pi}_{T H, t+1} \\
&+\left(1-\varphi_{T H} \beta\right) \frac{1-\varphi_{T H}}{\varphi_{T H}}\left[\begin{array}{c}
-(1-\zeta) \widehat{e}_{t}+\widehat{W}_{T H, t}-\widehat{\widetilde{P}}_{T H, t}-\frac{1}{\alpha_{T}} \cdot \widehat{z}_{T H, t} \\
+\frac{1-\alpha_{T}}{\alpha_{T}} k_{1} \widehat{Y}_{T H, t}^{H}+\frac{1-\alpha_{T}}{\alpha_{T}}\left(1-k_{1}\right) \widehat{Y}_{T H, t}^{F}
\end{array}\right] .
\end{aligned}
$$

Log-linearising (25) we obtain: 


$$
\pi_{T H, t}^{y}=k_{1} \pi_{T H, t}+\left(1-k_{1}\right)\left(\widehat{e}_{t}-\widehat{e}_{t-1}+\pi_{T H, t}^{*}\right)
$$

Using $P_{T H, t}^{*}=\frac{\widetilde{P}_{T H, t}}{e_{t}^{\zeta}}$, it is easy to show that:

$$
\tilde{\pi}_{T H, t}=\pi_{T H, t}^{*}+\zeta\left(\widehat{e}_{t}-\widehat{e}_{t-1}\right)
$$

By substituting Equations (24), (43) and (44) into Equation (41) we obtain:

$$
\begin{aligned}
& \pi_{T H, t}+\eta_{T} \frac{1-\alpha_{T}}{\alpha_{T}}\left[\pi_{T H, t}^{y}-\left(1-k_{1}\right)(1-\zeta)\left(\widehat{e}_{t}-\widehat{e}_{t-1}\right)\right] \\
& =\beta E_{t} \pi_{T H, t+1}+\eta_{T} \frac{1-\alpha_{T}}{\alpha_{T}} \beta E_{t}\left[\pi_{T H, t+1}^{y}-\left(1-k_{1}\right)(1-\zeta)\left(\widehat{e}_{t+1}-\widehat{e}_{t}\right)\right] \\
& +\left(1-\varphi_{T H} \beta\right) \frac{1-\varphi_{T H}}{\varphi_{T H}}\left[\widehat{W}_{T H, t}-\widehat{P}_{T H, t}-\frac{1}{\alpha_{T}} \cdot \widehat{z}_{T H, t}+\frac{1-\alpha_{T}}{\alpha_{T}} \widehat{Y}_{T H, t}\right]
\end{aligned}
$$

and by substituting Equations (24), (43) and (44) into Equation (42) we obtain:

$$
\begin{aligned}
& \eta_{T} \frac{1-\alpha_{T}}{\alpha_{T}}\left[\pi_{T H, t}^{y}-\left(1-k_{1}\right)(1-\zeta)\left(\widehat{e}_{t}-\widehat{e}_{t-1}\right)\right]+\pi_{T H, t}^{*}+\zeta\left(\widehat{e}_{t}-\widehat{e}_{t-1}\right) \\
& =\eta_{T} \frac{1-\alpha_{T}}{\alpha_{T}} \beta E_{t}\left[\pi_{T H, t+1}^{y}-\left(1-k_{1}\right)(1-\zeta)\left(\widehat{e}_{t+1}-\widehat{e}_{t}\right)\right]+\beta E_{t}\left[\pi_{T H, t+1}^{*}+\zeta\left(\widehat{e}_{t+1}-\widehat{e}_{t}\right)\right] \\
& +\left(1-\varphi_{T H} \beta\right) \frac{1-\varphi_{T H}}{\varphi_{T H}}\left[-(1-\zeta) \widehat{e}_{t}+\widehat{W}_{T H, t}-\widehat{P}_{T H, t}^{*}-\zeta \widehat{e}_{t}-\frac{1}{\alpha_{T}} \cdot \widehat{z}_{T H, t}+\frac{1-\alpha_{T}}{\alpha_{T}} \widehat{Y}_{T H, t}\right]
\end{aligned}
$$

Next, we can multiply (45) by $k_{1}$ and $(46)$ by $\left(1-k_{1}\right)$, sum the two equations and after some simplifications we arrive at the forward-looking equation for total inflation in the Home traded goods sector:

$$
\begin{aligned}
& \pi_{T H, t}^{y}-(1-\zeta)\left(1-k_{1}\right)\left(\widehat{e}_{t}-\widehat{e}_{t-1}\right) \\
= & \beta E_{t}\left[\pi_{T H, t+1}^{y}-(1-\zeta)\left(1-k_{1}\right)\left(\widehat{e}_{t+1}-\widehat{e}_{t}\right)\right] \\
& +\left(\frac{1-\varphi_{T H} \beta}{1+\eta_{T} \frac{1-\alpha_{T}}{\alpha_{T}}} \frac{1-\varphi_{T H}}{\varphi_{T H}}\right)\left[\widehat{W}_{T H, t}-\widehat{P}_{T H, t}^{y}-\frac{1}{\alpha_{T}} \cdot \widehat{z}_{T H, t}+\frac{1-\alpha_{T}}{\alpha_{T}} \widehat{Y}_{T H, t}\right] .
\end{aligned}
$$

We can write variations in the total real marginal cost $\left(M C_{T H}\right)$ in sector $T H$ as:

$$
\widehat{M C}_{T H, t}=\widehat{W}_{T H, t}-\widehat{P}_{T H, t}^{y}-\frac{1}{\alpha_{T}} \cdot \widehat{z}_{T H, t}+\frac{1-\alpha_{T}}{\alpha_{T}} \widehat{Y}_{T H, t}
$$

In the particular case of constant returns to labour $\left(\alpha_{T}=1\right)$, the level of output does not affect real marginal costs. 
Following analogous steps, we can derive also the forward-looking equation for inflation in the Home nontraded sector:

$$
\pi_{N, t}=\beta E_{t} \pi_{N, t+1}+\left(\frac{1-\varphi_{N} \beta}{1+\eta_{N} \frac{1-\alpha_{N}}{\alpha_{N}}} \frac{1-\varphi_{N}}{\varphi_{N}}\right)\left(\widehat{W}_{N, t}-\widehat{P}_{N, t}-\frac{1}{\alpha_{N}} \cdot \widehat{z}_{N, t}+\frac{1-\alpha_{N}}{\alpha_{N}} \widehat{Y}_{N, t}\right) .
$$

If we make use of the simplifying assumptions $\theta=1, \varphi_{T H}=\varphi_{N}=\varphi, \eta_{T H}=\eta_{N}=\eta$, and $\alpha_{T H}=\alpha_{N}=\alpha$ then the following relationship holds:

$$
\begin{aligned}
& \pi_{T H, t}^{y}-\pi_{N, t}-\delta(1-\zeta)\left(\widehat{e}_{t}-\widehat{e}_{t-1}\right) \\
= & \beta E_{t}\left[\pi_{T H, t+1}^{y}-\pi_{N, t+1}-\delta(1-\zeta)\left(\widehat{e}_{t+1}-\widehat{e}_{t}\right)\right] \\
+ & \left(\frac{1-\varphi \beta}{1+\eta \frac{1-\alpha}{\alpha}} \frac{1-\varphi}{\varphi}\right)\left[\begin{array}{c}
\widehat{W}_{T H, t}-\widehat{P}_{T H, t}^{y}-\frac{1}{\alpha} \cdot \widehat{z}_{T H, t}+\frac{1-\alpha}{\alpha} \widehat{Y}_{T H, t} \\
-\left(\widehat{W}_{N, t}-\widehat{P}_{N, t}-\frac{1}{\alpha} \cdot \widehat{z}_{N, t}+\frac{1-\alpha}{\alpha} \widehat{Y}_{N, t}\right)
\end{array}\right] .
\end{aligned}
$$

Moreover, if we assume that the economy is at the steady state in period $t-1$, then $\pi_{T H, t}^{y}=$ $\widehat{P}_{T H, t}^{y}$ and $\pi_{N, t}=\widehat{P}_{N, t}$, therefore we can write:

$$
\begin{aligned}
& \widehat{P}_{T H, t}^{y}-\widehat{P}_{N, t}=\delta(1-\zeta) \widehat{e}_{t} \\
& +\beta E_{t}\left[\pi_{T H, t+1}^{y}-\pi_{N, t+1}-\delta(1-\zeta)\left(\widehat{e}_{t+1}-\widehat{e}_{t}\right)\right] \\
& +\left(\frac{1-\varphi \beta}{1+\eta \frac{1-\alpha}{\alpha}} \frac{1-\varphi}{\varphi}\right)\left[\begin{array}{c}
\widehat{W}_{T H, t}-\widehat{P}_{T H, t}^{y}-\frac{1}{\alpha} \cdot \widehat{z}_{T H, t}+\frac{1-\alpha}{\alpha} \widehat{Y}_{T H, t} \\
-\left(\widehat{W}_{N, t}-\widehat{P}_{N, t}-\frac{1}{\alpha} \cdot \widehat{z}_{N, t}+\frac{1-\alpha}{\alpha} \widehat{Y}_{N, t}\right)
\end{array}\right] .
\end{aligned}
$$


Recent UWE Economics Papers

See http://www1.uwe.ac.uk/bl/research/bristoleconomicanalysis for a full list.

$\underline{2016}$

1609 Pricing Behaviour and the Role of Trade Openness in the Transmission of Monetary Shocks Laura Povoledo

1608 Measuring compliance with minimum wages

Felix Ritchie, Michail Veliziotis, Hilary Drew and Damian Whittard

1607 Can a change in attitudes improve effective access to administrative data for research? Felix Ritchie

1606 Application of ethical concerns for the natural environment into business design: a novel business model framework

Peter Bradley, Glenn Parry and Nicholas O'Regan

1605 Refining the application of the FLQ Formula for estimating regional input coefficients: an empirical study for South Korean regions

Anthony T. Flegg and Timo Tohmo

1604 Higher education in Uzbekistan: reforms and the changing landscape since independence Kobil Ruziev and Davron Rustamov

1603 Circular econmoy

Peter Bradley

1602 Do shadow banks create money? 'Financialisation' and the monetary circuit Jo Michell

1601 Five Safes: designing data access for research

Tanvi Desai, Felix Ritchie and Richard Welpton

1509 Debt cycles, instability and fiscal rules: a Godley-Minsky model Yannis Dafermos

1508 Evaluating the FLQ and AFLQ formulae for estimating regional input coefficients: empirical evidence for the province of Córdoba, Argentina

Anthony T. Flegg, Leonardo J. Mastronardi and Carlos A. Romero

1507 Effects of preferential trade agreements in the presence of zero trade flows: the cases of China and India

Rahul Sen, Sadhana Srivastava and Don J Webber

1506 Using CHARM to adjust for cross-hauling: the case of the Province of Hubei, China Anthony T. Flegg, Yongming Huang and Timo Tohmo

1505 University entrepreneurship education experiences: enhancing the entrepreneurial ecosystems in a UK city-region

Fumi Kitagawa, Don J. Webber, Anthony Plumridge and Susan Robertson

1504 Can indeterminacy and self-fulfilling expectations help explain international business cycles? Stephen McKnight and Laura Povoledo

1503 User-focused threat identification for anonymised microdata Hans-Peter Hafner, Felix Ritchie and Rainer Lenz 
1502 Reflections on the one-minute paper

Damian Whittard

1501 Principles- versus rules-based output statistical disclosure control in remote access environments Felix Ritchie and Mark Elliot

1413 Addressing the human factor in data access: incentive compatibility, legitimacy and costeffectiveness in public data resources

Felix Ritchie and Richard Welpton

1412 Resistance to change in government: risk, inertia and incentives

Felix Ritchie

1411 Emigration, remittances and corruption experience of those staying behind Artjoms Ivlevs and Roswitha M. King

1410 Operationalising 'safe statistics': the case of linear regression Felix Ritchie

1409 Is temporary employment a cause or consequence of poor mental health? Chris Dawson, Michail Veliziotis, Gail Pacheco and Don J Webber

1408 Regional productivity in a multi-speed Europe Don J. Webber, Min Hua Jen and Eoin O’Leary

1407 Assimilation of the migrant work ethic

Chris Dawson, Michail Veliziotis, Benjamin Hopkins

1406 Empirical evidence on the use of the FLQ formula for regionalizing national input-output tables: the case of the Province of Córdoba, Argentina

Anthony T. Flegg, Leonardo J. Mastronardi and Carlos A. Romero

1405 Can the one minute paper breathe life back into the economics lecture?

Damian Whittard

1404 The role of social norms in incentivising energy reduction in organisations Peter Bradley, Matthew Leach and Shane Fudge

1403 How do knowledge brokers work? The case of WERS Hilary Drew, Felix Ritchie and Anna King

1402 Happy moves? Assessing the impact of subjective well-being on the emigration decision Artjoms Ivlevs

1401 Communist party membership and bribe paying in transitional economies Timothy Hinks and Artjoms Ivlevs

1315 Global economic crisis and corruption experience: Evidence from transition economies Artjoms Ivlevs and Timothy Hinks

1314 A two-state Markov-switching distinctive conditional variance application for tanker freight returns Wessam Abouarghoub, Iris Biefang-Frisancho Mariscal and Peter Howells

1313 Measuring the level of risk exposure in tanker shipping freight markets Wessam Abouarghoub and Iris Biefang-Frisancho Mariscal 